AperTO - Archivio Istituzionale Open Access dell'Università di Torino

\title{
A thermodynamic assessment of LiBH4
}

\section{This is the author's manuscript}

Original Citation:

Availability:

This version is available http://hdl.handle.net/2318/130279

since 2016-08-20T17:08:10Z

Published version:

DOI:10.1016/j.calphad.2012.08.005

Terms of use:

Open Access

Anyone can freely access the full text of works made available as "Open Access". Works made available under a Creative Commons license can be used according to the terms and conditions of said license. Use of all other works requires consent of the right holder (author or publisher) if not exempted from copyright protection by the applicable law. 
This Accepted Author Manuscript (AAM) is copyrighted and published by Elsevier. It is posted here by agreement between Elsevier and the University of Turin. Changes resulting from the publishing process - such as editing, corrections, structural formatting, and other quality control mechanisms - may not be reflected in this version of the text. The definitive version of the text was subsequently published in CALPHAD, 39, 2012, 10.1016/j.calphad.2012.08.005.

You may download, copy and otherwise use the AAM for non-commercial purposes provided that your license is limited by the following restrictions:

(1) You may use this AAM for non-commercial purposes only under the terms of the CC-BY-NC-ND license.

(2) The integrity of the work and identification of the author, copyright owner, and publisher must be preserved in any copy.

(3) You must attribute this AAM in the following format: Creative Commons BY-NC-ND license (http://creativecommons.org/licenses/by-nc-nd/4.0/deed.en), 10.1016/j.calphad.2012.08.005

The publisher's version is available at:

http://linkinghub.elsevier.com/retrieve/pii/S0364591612000740

When citing, please refer to the published version.

Link to this full text:

http://hdl.handle.net/2318/130279 


\title{
A thermodynamic assessment of $\mathrm{LiBH}_{4}$
}

\author{
Abdelouahab El Kharbachi ${ }^{a}$, Eugenio Pinatel ${ }^{b}$, Ioana Nuta ${ }^{\mathrm{a}, \mathrm{n}}$, Marcello Baricco ${ }^{\mathrm{b}}$ \\ a Laboratoire de la Science et Inge'nierie des Mate'riaux et Proce'de's (SIMaP), Grenoble-INP, 1130 rue de la Piscine, Domaine Universitaire, BP 75, 38402 Saint Martin d'Heres, \\ France ${ }^{b}$ Dipartimento di Chimica and NIS, Universita di Torino, via P. Giuria 9, 10125 Torino, Italy
}

a b s tract

Thermodynamic data of the $\mathrm{LiBH}_{4}$ compound are reviewed and critically assessed. On the basis of literature data of heat capacity, heat of formation, temperature and enthalpy of phase transitions, a CALPHAD optimized Gibbs energy function is derived for the condensed phases i.e. orthorhombic and hexagonal solid phases and the liquid phase. Considering hydrogen as an ideal gas phase, the thermodynamics of decomposition reactions of $\mathrm{LiBH}_{4}$ is calculated, showing good agreement with existing experimental data.

\section{Introduction}

Lithium borohydride $\left(\mathrm{LiBH}_{4}\right)$ is an attractive candidate for energy storage, due to its high gravimetric $(18.5 \mathrm{wt} \%)$ and volu-metric $\left(121 \mathrm{~kg} \mathrm{H}_{2} / \mathrm{m}^{3}\right)$ hydrogen density. Hydrogen desorption temperature of $\mathrm{LiBH}_{4}$ is too high for practical applications [1] and, as similar chemical-hydride-based energy carriers, it is difficult to re-hydrogenate [2]. For these reasons, several attempts have been recently carried out in order to promote hydrogen desorption and absorption processes. Because electronic structure calculations indicate that a charge transfer from the metal cations $\mathrm{M}^{\mathrm{n}} \mathrm{b}$ to the [BH $\mathrm{H}_{4}$ ] anions is a key feature determining the thermodynamic stability of $\mathrm{M}\left(\mathrm{BH}_{4}\right)_{\mathrm{n}}$, cation and anion substitutions in LiBH 4 have been investigated [3-7]. Moreover, a destablization of $\mathrm{LiBH}_{4}$ via reaction with a second hydride system has been suggested, in order to reduce the Gibbs Free Energy (GFE) difference between hydrogenated and de-hydrogenated species [2,8]. As an example, $\mathrm{LiBH}_{4}-\mathrm{MgH}_{2}$ reactive hydride composite has been deeply studied [5,9]. Even if the mechanisms of dehydrogenation reactions have not been clarified yet, the addition of a small amount of a promoter (e.g. $\mathrm{SiO}_{2}, \mathrm{Mg}, \mathrm{Al}, \mathrm{TiCl}_{3}$ ) has been demonstrated to accelerate the desorption reactions [2,5]. More recently, the confinement of LiBH 4 in nanosized scaffolds has been shown to be a suitable approach to reduce the desorption temperature [10]. Finally, the synthesis of nanosized LiBH $\mathrm{H}_{4}$ particles allowed the decreasing of the desorption temperature to values close to room temperature [11].

In complex hydrides the challenge is to identify stable dehy-drogenation products and possible intermediate compounds. Thermodynamic modeling [12] is a modern tool that allows the prediction of equilibrium behavior of multicomponent systems, decreasing the extent of expensive or difficult experimental studies. It is based on the availability of thermodynamic data-bases describing the GFE for each phase of a system as a function of temperature, pressure and composition. So, a good description of the GFE for each stable phase of $\mathrm{LiBH}_{4}$ is very important to understand the dehenation behavior of several systems containing this compound [13].

$\mathrm{LiBH}_{4}$ shows three condensed phases: an orthorhombic struc-ture from room temperature to $383 \mathrm{~K}$, a hexagonal structure from $383 \mathrm{~K}$ to $551 \mathrm{~K}$ and a liquid phase at higher temperatures [1,2].

Thermodynamic properties of $\mathrm{LiBH}_{4}$ have been widely inves-tigated with several experimental and theoretical methods [14-19], as summarized in Table 1. GFE functions for $\mathrm{LiBH}_{4}$ are available in commercial and open databases [20,21] and they should be used to estimate the thermodynamics of hydrogen desorption. However, despite the huge availability of data, ther-modynamic functions used in current databases [20,21] are out of date. In fact, they are still based on data reported in JANAF tables [22], which contain values estimated by comparison with $\mathrm{NaBH}_{4}$. Moreover, data related to polymorphous transformation and melting of this compound are not reported in JANAF tables.

In the present work, thermodynamic properties for $\mathrm{LiBH}_{4}$ have been collected from the literature considering also ab-initio calculations, widely applied in recent years in order to estimate structural and thermodynamic properties [23-28]. Literature data, together with calorimetric measurements of molar heat capacity $\mathrm{C}_{\mathrm{p}, \mathrm{m}}$ of $\mathrm{LiBH}_{4}$ reported recently by present authors [19], 
Table 1

Literature thermodynamic studies performed on the $\mathrm{LiBH}_{4}$ compound, altogether with experimental methods, temperature range, conditions of measurements and sample purity.

\begin{tabular}{|c|c|c|c|c|c|}
\hline $\begin{array}{l}\text { Authors [Ref.], } \\
\text { (year) }\end{array}$ & Method & T range $(\mathrm{K})$ & Conditions & $\begin{array}{l}\text { Sample purity } \\
(\mathrm{wt} \%)\end{array}$ & Notes \\
\hline $\begin{array}{l}\text { Davis et al. [14], } \\
\text { (1949) }\end{array}$ & $\begin{array}{l}\text { Dissolution in hydrochloric } \\
\text { acid and drop calorimetry }\end{array}$ & $273-298.15$ & $\mathrm{Ni}$ crucible under dry $\mathrm{N}_{2}$ & $\begin{array}{l}\text { Purified } \\
\text { up to } 98.72\end{array}$ & Instability of the stored compound \\
\hline $\begin{array}{l}\text { Hallett and } \\
\text { Johnston [15], } \\
\text { (1953) }\end{array}$ & $\begin{array}{l}\text { Nernst vacuum } \\
\text { calorimetry }\end{array}$ & $15-303$ & $\begin{array}{l}\text { Sample filled in the calorimeter container } \\
\text { and sealed under He pressure }\end{array}$ & $\begin{array}{l}\text { Purified under } \\
\mathrm{N}_{2} \text { up to } \\
99.7\end{array}$ & $\begin{array}{l}\text { Purification process according } \\
\text { to Ref. [14] }\end{array}$ \\
\hline $\begin{array}{l}\text { Fedneva et al. } \\
\text { [35], (1964) }\end{array}$ & $\begin{array}{l}\text { Differential thermal } \\
\text { analysis (DTA) }\end{array}$ & $298.15-873$ & $\begin{array}{l}\text { Under dry } \mathrm{H}_{2} \text { at } 0.05 \mathrm{~K} \mathrm{~s}^{1} \text { flow rate } \\
\text { (1 bar) }\end{array}$ & $97-98$ & Synthesized from $\mathrm{LiH}_{\text {and }} \mathrm{BF}_{3}$ ether \\
\hline $\begin{array}{l}\text { Stasinevich and } \\
\text { Egorenko [16], } \\
\text { (1968) }\end{array}$ & DTA & $300-983$ & $\begin{array}{l}\text { Under various } \mathrm{H}_{2} \text { pressures/ } \mathrm{p} 1 \\
(1.0133-10.133 \text { bar) }\end{array}$ & 98 & Four endothermic events were observed \\
\hline $\begin{array}{l}\text { Semenenko et al. } \\
\text { [40], (1971) }\end{array}$ & $\begin{array}{l}\text { Thermal analysis/ XRD } \\
\text { Phase diagram } \\
\text { determination }\end{array}$ & $300-620$ & $\begin{array}{l}\text { Samples in sealed ampoules under } \\
\text { vacuum }(0.2105 \mathrm{bar} / \mathrm{p} 1) \\
0.08334 \mathrm{~K} \mathrm{~s}{ }^{1} \text { rate }\end{array}$ & 98.7 & $\begin{array}{l}\text { Annealed mixtures }\left(\mathrm{LiBH}_{4}-\mathrm{NaBH}_{4}\right) \\
\text { at varying compositions: eutectic } \\
\text { observed }\end{array}$ \\
\hline $\begin{array}{l}\text { Pistorius [36], } \\
\text { (1974) }\end{array}$ & High pressure/ DTA & $298.15-823$ & $\begin{array}{l}\text { Under high pressure piston in dry box up } \\
\text { to } 5 \mathrm{GPa}\end{array}$ & & $\begin{array}{l}\text { Thermodynamic parameters deduced by } \\
\text { extrapolation to zero pressure }\end{array}$ \\
\hline $\begin{array}{l}\text { Gorbunov et al. } \\
\text { [17], (1984) }\end{array}$ & $\begin{array}{l}\text { Adiabatic and differential } \\
\text { scanning calorimetry (DSC) }\end{array}$ & $10-450$ & $\begin{array}{l}\text { Under vacuum and measurements } \\
\text { referred to } \mathrm{Cl}_{\mathrm{p}} \text { of } \mathrm{Al}_{2} \mathrm{O}_{3}\end{array}$ & 99.3 & $\begin{array}{l}\text { DSC data were } 5 \% \text { higher than those } \\
\text { obtained by adiabatic measurements }\end{array}$ \\
\hline $\begin{array}{l}\text { Orimo et al. [56], L } \\
\quad(2005)\end{array}$ & $\begin{array}{l}\text { DSC/ Thermal desorption } \\
\text { (TD)/ Raman spectroscopy/ } \\
\text { powder-XRD }\end{array}$ & $300-800$ & $\begin{array}{l}\text { DSC under } 0.1 \mathrm{MPa} \text { of } \mathrm{H}_{2} \text { heating rate } \\
10 \mathrm{~K} \min 1\end{array}$ & 95 & \\
\hline $\begin{array}{l}\text { Orimo et al. [46], T } \\
\quad(2006)\end{array}$ & $\begin{array}{l}\text { Thermogravimetry (TG), } \\
\text { DTA/ Mass spectrometry } \\
\text { (MS) }\end{array}$ & $300-900$ & $\begin{array}{l}\text { TG-DTA } \mathrm{n} 150 \mathrm{ml} \mathrm{min}{ }^{1} \mathrm{He} \text { flow } \\
5 \mathrm{~K} \mathrm{~min}\end{array}$ & 95 & \\
\hline $\begin{array}{l}\text { Zuttel" et al. [1], } \\
\quad(2007)\end{array}$ & $\mathrm{TD} / \mathrm{MS}$ & $298.15-773$ & Heating rate $0.5 \mathrm{~K} \mathrm{~min}{ }^{1}$ & 95 & \\
\hline $\begin{array}{l}\text { Mauron et al. } \\
\text { [44], (2008) }\end{array}$ & TD/ Dynamic PCT & $650-800$ & $\begin{array}{l}\text { Extrapolation of the equilibrium pressure } \\
\text { for } \mathrm{H}_{2} \text { flow equal to } 0\end{array}$ & 95 & $\begin{array}{l}\text { For low T equilibrium conditions not } \\
\text { fulfilled }\end{array}$ \\
\hline $\begin{array}{r}\text { Filinchuk et al. } \\
\text { [42], (2008) }\end{array}$ & HR-XRD & $80-500$ & $\begin{array}{l}\text { Sample in thin glass capillaries under } \\
\text { protective oil }\end{array}$ & 95 & Sample frozen using cryogenic system \\
\hline $\begin{array}{l}\text { Price et al. [41], } \\
\quad(2009)\end{array}$ & DSC/DTA & $298.15-873$ & $\begin{array}{l}\text { Under Ar at } 0.08334 \mathrm{~K} \mathrm{~s}^{1} \text { rate in } \mathrm{Al} \\
\text { hermetically sealed pans }\end{array}$ & 95 & \\
\hline $\begin{array}{l}\text { Pendolino et al. } \\
\text { [37], (2009) }\end{array}$ & DSC/TGA & $298.15-873$ & $\begin{array}{l}\text { Under } \mathrm{H}_{2} \text { pressure at } 0.1834 \mathrm{~K} \mathrm{~s}^{1} \text { rate in } \\
\mathrm{Al} \text { crucible }\end{array}$ & 95 & $\begin{array}{l}\text { Variable heating rates for activation } \\
\text { energy estimation }\end{array}$ \\
\hline $\begin{array}{l}\text { El Kharbachi [19], } \\
\text { (2011) }\end{array}$ & DSC & $298-553 \mathrm{~K}$ & Under $\mathrm{Ar}$ in $\mathrm{Al}$ hermetically sealed pans & 98.1 & $\begin{array}{l}2 \text { scanning methods: "linear temperature } \\
\text { ramp method" and "the enthalpy } \\
\text { method" }\end{array}$ \\
\hline
\end{tabular}

Table 2

$\mathrm{LiBH}_{4}$ phase transitions temperatures and enthalpies. Values in brackets have not been considered in the average. The exclusion of these values is due to big discrepancies with respect to the other data, to an unclear connection to experiments or because data have been reported referring to other publications (in this case only the original data have been considered).

\begin{tabular}{|c|c|c|c|c|}
\hline \multirow[t]{2}{*}{ Authors [Ref.], (year) } & \multicolumn{2}{|l|}{ Polymorphous transition } & \multicolumn{2}{|l|}{ Melting } \\
\hline & $\mathrm{T}_{\mathrm{trs}}(\mathrm{K})$ & $\mathrm{DH}_{\text {trs }}\left(\mathrm{kJ}\right.$ mol $\left.{ }^{1}\right)$ & $\mathrm{T}_{\mathrm{m}}(\mathrm{K})$ & $\mathrm{DH}_{\mathrm{m}}\left(\mathrm{kJ}\right.$ mol $\left.{ }^{1}\right)$ \\
\hline Schlesinger [39], (1940) & & & 548 & \\
\hline Fedneva [35], (1964) & 381 & & 541 & \\
\hline Stasinevich [16], (1968) & 38373 & & 55373 & \\
\hline Semenenko [40], (1971) & 381 & & 555 & \\
\hline Pistorius [36], (1974) & 381.570 .5 & 6.303 & (588) & \\
\hline Gorbunov [17], (1984) & 385.6 & 6.22970 .084 & & \\
\hline JANAF [22], (1998) & & & (750) & \\
\hline Zuttel [43], (2003) & (378) & & & \\
\hline Gavrichev [59], (2003) & 384.6 & & & \\
\hline Zuttel [60], (2004) & & & (550) & \\
\hline Orimo [56], (2005) & 380 & & 550 & \\
\hline Zuttel $^{*}[1],(2007)$ & (391) & $(4.18)$ & $(560)$ & (7.56) \\
\hline Zarkevic [38], (2008) & (381) & 4.6 & (553) & 6.3 \\
\hline Filinchuk [42], (2008) & 381 & & & \\
\hline Price [41], (2009) & 383 & 4.3870 .04 & 552 & 8.03 \\
\hline Pendolino [37], (2009) & 383 & & 553 & \\
\hline El Kharbachi [19], (2011) & 386.671 & 5.06970 .076 & 554 & \\
\hline Lang [61], (2012) & 384.5 & & & \\
\hline This work (linear extrapolation from Pistorius [36]) & $(381)$ & & & \\
\hline Average & 382.75 & 5.316 & 550.75 & 7.165 \\
\hline St. deviation & 2.11 & 0.90 & 4.53 & 1.223 \\
\hline Selected value & 38372 & 5.370 .9 & 55175 & 7.271 .2 \\
\hline Calculated entropy (DS1/4DH/T) & $\mathrm{DS}_{\mathrm{trs}} 1 / 41472 \mathrm{~J} \mathrm{~K}^{1} \mathrm{~mol}{ }^{1}$ & & $\mathrm{DS}_{\mathrm{m}}{ }^{1 / 41372 \mathrm{~J} \mathrm{~K}^{1}}{ }_{\mathrm{mol}}^{1}$ & \\
\hline
\end{tabular}


Table 3

Experimental and calculated enthalpy and entropy values for different $\mathrm{LiBH}_{4}$ decomposition reactions. For sake of comparison, data are reported per mol of $\mathrm{H}_{2}$.

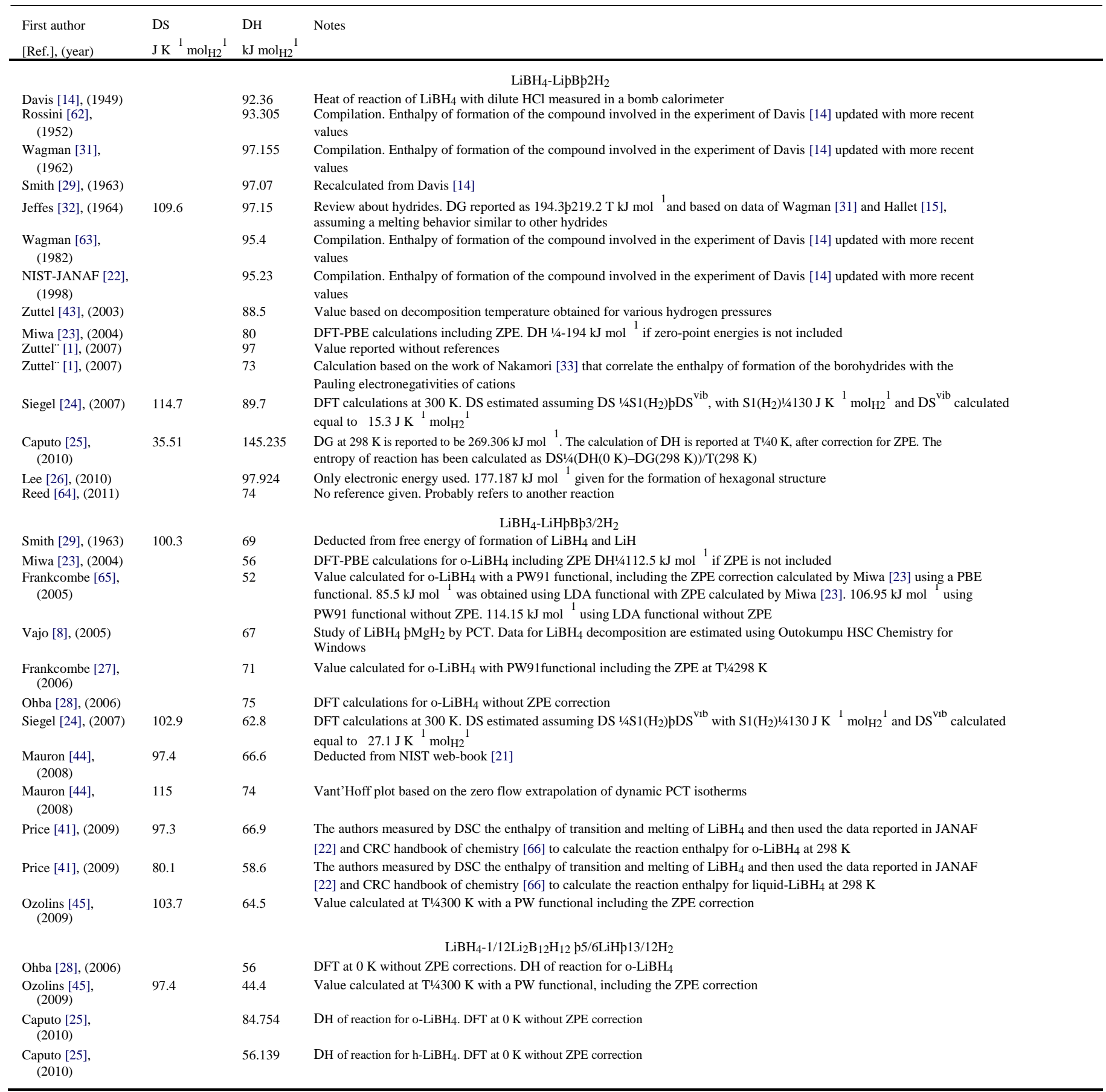


have been considered. According to the CALPHAD method, the GFE functions for orthorhombic, hexagonal and liquid phases of LiBH 4 have been obtained. Finally, from the calculated GFE, possible decomposition reaction paths have been estimated in order to describe hydrogen absorption and desorption processes.

2. Review of $\mathrm{LiBH}_{4}$ thermodynamic properties

Table 2 summarizes experimental results of the polymorphous phase transition (orthorhombic-to-hexagonal) and melting of $\mathrm{LiBH}_{4}$. Table 3 gives experimental and calculated enthalpy and

entropy values for different decomposition reactions of $\mathrm{LiBH}_{4}$. For sake of comparison, data are reported per mol of $\mathrm{H}_{2}$. In the following, experimental techniques and theoretical methods used to obtain various data will be described in details.

\section{1. $\mathrm{LiBH}_{4}$ solid state}

\subsubsection{Standard molar heat capacity and entropy}

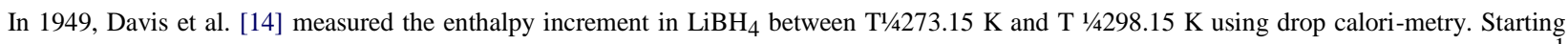
from their data, the value of the molar heat capacity can be inferred at an average temperature of $285.6 \mathrm{~K}_{\text {a }} \mathrm{C}_{\mathrm{p}, \mathrm{m}}(285.6 \mathrm{~K})^{1 / 4 \mathrm{DQ} / \mathrm{DT}} \mathrm{T}^{1 / 476.670 .9} \mathrm{~J} \mathrm{~K}{ }^{1}$ $\mathrm{mol}^{1}$. At lower tempera-tures (i.e. 15-303 K), Hallett and Johnston [15] measured the heat capacity of $\mathrm{LiBH}_{4}$ by adiabatic calorimetry and proposed, for the standard molar heat capacity and entropy at $298.15 \mathrm{~K}$, values of $\mathrm{C}_{\mathrm{p}, \mathrm{m}}(298.15 \mathrm{~K})^{1 / 4} / 42.563 \mathrm{~J} \mathrm{~K}{ }^{1} \mathrm{~mol}^{1}$ and S1(298.15 K)1/475.8607 0.125 J K ${ }^{1} \mathrm{~mol}^{1}$, respectively. Using literature values for the absolute entropy of elements, Smith and Bass [29] recalculated S1(298.15 K) equal to $75.85 \mathrm{~J} \mathrm{~K}{ }^{1}$ mol ${ }^{1}$. Gorbunov et al. [17] measured the heat capacity of the compound between $10 \mathrm{~K}$ and $450 \mathrm{~K}$, using both adiabatic and differential scanning calorimetry (DSC) under vacuum. Up to $350 \mathrm{~K}$, their results agree with previous measurements of Hallett and Johnston [15] but their values were lower of about $2.5 \%$ at $298.15 \mathrm{~K}$, giving $\mathrm{C} 1_{\mathrm{p}, \mathrm{m}}(298.15 \mathrm{~K})^{1 / 4}$

$80.46 \mathrm{~J} \mathrm{~K}^{1} \mathrm{~mol}^{1}$. In addition, the value of standard entropy was lower than that $\quad$ reported in Ref. [15], i.e. S1(298.15 K $)^{1 / 4}$

73.7 J K ${ }^{1} \mathrm{~mol}^{1}$. Above room temperature, experimental values for heat capacity of orthorhombic and hexagonal phases have been obtained by several authors, as recently discussed in Ref. [19]. The present authors [19] determined the molar heat capacity of $\mathrm{LiBH}_{4}$ by DSC in the 298.15-520 $\mathrm{K}$ temperature range, giving a value of $\mathrm{C}_{\mathrm{p}, \mathrm{m}}(298.15 \mathrm{~K})$ equal to $81.34 \mathrm{~J} \mathrm{~K}^{1} \mathrm{~mol}{ }^{1}$, in good agreement with the average of values reported from previous measurements $[15,17]$. Kim et al. [30] calculated by ab-initio methods the molar heat capacity for the hexagonal and orthorhombic phases from 0 to $1000 \mathrm{~K}$. The agreement with the experimental data is limited, mainly at high temperatures. In fact, around room temperature, the $\mathrm{C} 1_{\mathrm{p}, \mathrm{m}}$ calculated for the orthorhombic phase is about $10 \mathrm{~J} \mathrm{~K} \mathrm{~mol}{ }^{1}$ lower that determined experimentally, whereas for the hexagonal phase at $450 \mathrm{~K}$ there is a difference of about $23 \mathrm{~J} \mathrm{~K}^{1} \mathrm{~mol}^{1}$.

The values reported in JANAF tables [22] for the $\mathrm{C}_{\mathrm{p}, \mathrm{m}}(298.15 \mathrm{~K})$ and $\mathrm{S} 1(298.15 \mathrm{~K})$ are $82.539 \mathrm{~J} \mathrm{~K}{ }^{1}$ mol ${ }^{1}$ and $75.815 \mathrm{~J} \mathrm{~K}{ }^{1}$ mol ${ }^{1}$, respectively. The National Institute of Standard and Technology (NIST) chemistry WebBook [21] (also based on the JANAF compila-tion) gives $\mathrm{C}_{\mathrm{p}, \mathrm{m}}(298.15 \mathrm{~K})^{1 / 482.67 \mathrm{~J} \mathrm{~K}^{1}} \mathrm{~mol}^{1}$ and S1 $(298.15 \mathrm{~K})^{1 / 4} 75.88 \mathrm{~J} \mathrm{~K}^{1} \mathrm{~mol}^{1}$. The slight difference is likely due to the different equation used to fit experimental $\mathrm{C}_{\mathrm{p}, \mathrm{m}}$ data. It is worth noting that data of molar heat capacity reported in JANAF tables [22] below $300 \mathrm{~K}$ are based on experimental values reported by Hallet and Johnston [15], but at higher temperatures they are estimated by comparison with $\mathrm{C}_{\mathrm{p}, \mathrm{m}}$ values of $\mathrm{NaBH}_{4}$ and, therefore, they are not supported by experimental data. A comparison of experimental data with various functions for molar heat capacity provided by the abovementioned authors is reported in Figure A1 in Appendix: Supplementary data.

On the basis of the review of the whole set of available data (as described below in the Thermodynamic modeling section) the values for $\mathrm{Cl}_{\mathrm{p}, \mathrm{m}}$ $(298.15 \mathrm{~K})$ and $\mathrm{S} 1(298.15 \mathrm{~K})$ assessed in the present work are $80.92 \mathrm{~J} \mathrm{~K}^{1} \mathrm{~mol}^{1}$ and $74.97 \mathrm{~J} \mathrm{~K}^{1} \mathrm{~mol}^{1}$, respectively.

\subsubsection{Standard enthalpy of formation}

The heat of formation of $\mathrm{LiBH}_{4}$ was determined in 1949 by Davis et al. [14] measuring in a bomb calorimeter the heat of dissolution in hydrochloric acid at $298.15 \mathrm{~K}$, according to

\section{$\mathrm{LiBH}_{4}$ p1:25ðHClU200H 2 OP p $1 / 23 \mathrm{H}_{2} \mathrm{O} \&$ p $1 \mathrm{H}_{2} \mathrm{O}-\mathrm{LiClU}_{6} 0 \mathrm{H}_{2} \mathrm{O}$}

\section{$\mathrm{pH}_{3} \mathrm{BO}_{3} \mathrm{U}_{1} \mathrm{H}_{2} \mathrm{Op0} 0: 25 ð \mathrm{HClU} 508 \mathrm{H}_{2} \mathrm{OP} \mathrm{p} 4 \mathrm{H}_{2}$}

The total heat effects were measured with a precision of $0.35 \%$. In order to calculate the dissolution enthalpy at $298.15 \mathrm{~K}$, the authors measured the heat capacity of the reactants and products using drop calorimetry [14]. The enthalpy of reaction (1) was determined to be $301.54 \mathrm{~kJ}$ mol ${ }^{1}$, so that a value of the standard heat of formation, $\mathrm{D}_{\mathrm{f}} \mathrm{H} 1(298.15 \mathrm{~K})^{1 / 4} 184.7271 .25 \mathrm{~kJ}$ mol ${ }^{1}$ was given for orthorhombic $\mathrm{LiBH}_{4} . \mathrm{Because}_{\mathrm{f}} \mathrm{D}_{\mathrm{f}} \mathrm{for}_{3} \mathrm{H}_{3} \mathrm{BO} \mathrm{O}_{3}$ $\mathrm{NH}_{2} \mathrm{O}$ was calculated from $\mathrm{D}_{\mathrm{f}} \mathrm{H} 1$ of $\mathrm{B}_{2} \mathrm{O}_{3}$, known within $1 \%$ (i.e. $712 \mathrm{~kJ} \mathrm{~mol}{ }^{1}$ ), the authors reported an accuracy of the obtained value related to that of the heat of formation of $\mathrm{H}_{3} \mathrm{BO}_{3}$. The uncertainty on the heat of formation of this acid was rather large, as $\mathrm{D}_{\mathrm{f}} \mathrm{H} 1$ of $\mathrm{B}_{2} \mathrm{O}_{3}$ contri-butes by half of it. In addition, the reference state of boron was chosen as amorphous boron. From this experimental measurement, many revisions of the standard heat of formation of $\mathrm{LiBH}_{4}$ were reported in the literature. Different dissolution calorimetry experi-ments, either coming from literature or performed by the authors, provided the heat contribution of each compound in reaction (1) during mixing. Table A1 in Appendix: Supplementary data sum-marizes the 
heat of formation of the whole set of compounds involved in the calorimetric determinations of Davis et al. [14], as used in the compilations reported thereafter by many authors. It is clear that the main difference in the results comes from the heat of formation of boric acid, $\mathrm{H}_{3} \mathrm{BO}_{3}$, i.e. during its dissolution in water or indirectly from its basic products $\mathrm{B}_{2} \mathrm{O}_{3}$ and elemental boron. The compilation given by Wagman [31], adopted by NIST, suggested a standard heat of formation of $\mathrm{LiBH}_{4}$ as $\mathrm{D}_{\mathrm{f}} \mathrm{H} 1(298.15 \mathrm{~K}){ }^{1 / 4} 194.3170 .21 \mathrm{~kJ}$ mol ${ }^{1}$. This value has been maintained by Jeffes and McKerrell [32] in their thermodynamic tables. Using literature values, Smith and Bass [29] recalculated for $\mathrm{LiBH}_{4}$ a value of $\mathrm{D}_{\mathrm{f}} \mathrm{H} 1\left(298.15 \mathrm{~K}^{1} / 4\right.$ $194.01 \mathrm{~kJ} \mathrm{~mol}^{1}$. The experimental data of Davis et al. [14] have been also reviewed in JANAF tables [22], where a value of $\mathrm{D}_{\mathrm{f}} \mathrm{H} 1(298.15 \mathrm{~K}){ }^{1 / 4} 190.4670 .21 \mathrm{~kJ}$ ${ }^{1}{ }^{1}$ is reported. The reference state of boron in JANAF tables [22] is crystalline, whereas there is no information in the report made by Wagman [31]. The heat of transformation of amorphous boron from its crystalline counterpart is reported as $4.4 \mathrm{~kJ}$ mol ${ }^{1}$ [31]. Thus, it can be argued that the main reason of the difference between the two reported values, JANAF [22] and Wagman [31], is likely due to a different selection of reference state for boron.

First principle methods were used to calculate the "cohesion" energy of $\mathrm{LiBH}_{4}$ at $0 \mathrm{~K}$. Miwa et al. [23] calculated the heat of formation to be equal to $\mathrm{D}_{\mathrm{f}} \mathrm{H}(0 \mathrm{~K})^{1 / 4} 194 \mathrm{~kJ} \mathrm{~mol}^{1}$ and, when zero-point energies were included, it was given as $\mathrm{D}_{\mathrm{f}} \mathrm{H}(0 \mathrm{~K})^{1 / 4} 160 \mathrm{~kJ}$ mol ${ }^{1}$. Nakamori et al. [33] studied theoretically the stabi-lity of metal-borohydrides and found a correlation between the heat of formation and the Pauling electronegativity of the cation. The value reported for $\mathrm{LiBH}_{4}$ was $\mathrm{D}_{\mathrm{f}} \mathrm{H}(0 \mathrm{~K})^{1 / 4} 146 \mathrm{~kJ} \mathrm{~mol}^{1}$. Zuttel" et al. [1] provided a value of $\mathrm{D}_{\mathrm{f}} \mathrm{H}(0 \mathrm{~K})^{1 / 4} 194.15 \mathrm{~kJ}$ mol ${ }^{1}$, obtained from calculations of formation reaction, $\mathrm{LiHpBp} 3 / 2 \mathrm{H}_{2}{ }^{1 / 4} \mathrm{LiBH}_{4}$. Siegel et al. [24], using the VASP ab-initio calculations package, provided a value of $179.4 \mathrm{~kJ} \mathrm{~mol}^{1}$ for the heat of decomposition of $\mathrm{LiBH}_{4}$ to the parent elements $\left(\mathrm{BpLip} 2 \mathrm{H}_{2}\right)$ at $300 \mathrm{~K}$.

In the present assessment, the value reported by the JANAF compilation [22], $\mathrm{D}_{\mathrm{f}} \mathrm{H} 1(298.15 \mathrm{~K}){ }^{1 / 4} 190.4670 .21 \mathrm{~kJ}$ mol ${ }^{1}$, was selected. In fact, it is based on the single experimental measure-ment of enthalpy of formation [14] and updated with the most recent values for the formation enthalpy of the compounds involved in the calorimetric measurement.

\section{2. $\mathrm{LiBH}_{4}$ polymorphous transition}

\subsubsection{Transition temperature}

It is well established that the $\mathrm{LiBH}_{4}$ has a polymorphous transformation from orthorhombic to hexagonal structure [34]. The values of the phase transition temperature $\left(\mathrm{T}_{\text {trs }}\right.$ ) reported in the literature are collected in Table 2. Fedneva et al. [35] detected by DSC the presence of the polymorphous transition in the temperature range from $381 \mathrm{~K}$ to $385 \mathrm{~K}$. The $4 \mathrm{~K}$ range may be related to uncertainties in the baseline of the DSC peak, due to the effect of an unusual increase of the molar heat capacity, as discussed in details in Ref. [19]. Stasinevich and Egorenko [16] observed the phase transformation by Differential Thermal Ana-lysis (DTA) at different hydrogen pressures, from 1.0133 bar to 10.133 bar. The polymorphous phase

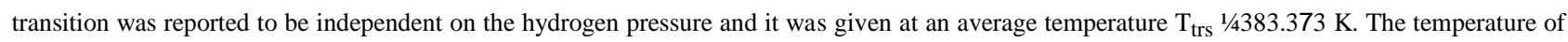
the polymorphous transition was also observed with DTA by Pistorius [36], who gives a value, averaged from 16 measurements, equal to $\mathrm{T}_{\text {trs }}$ $1 / 4381.570 .5 \mathrm{~K}$. In the same paper, the transition temperature was measured at various pressures by means of piston rotation technique. From these data, the orthorhombic-to-hexagonal tran-sition temperature may be calculated by linear extrapolation to $0.0001 \mathrm{GPa}$ pressure as $\mathrm{T}_{\text {trs }} 1 / 4381.670 .5 \mathrm{~K}$, as shown in Figure A2 in Appendix: Supplementary data. A value of $\mathrm{T}_{\text {trs }} 1 / 4383 \mathrm{~K}$ was obtained for the polymorphous transformation temperature by Pendolino et al. [37] using DSC. From a selection of collected data (see Table 2), an average selected value of $\mathrm{T}_{\text {trs }} 1 / 438372 \mathrm{~K}$ has been considered for the assessment.

\subsubsection{Polymorphous transition enthalpy and entropy}

From the analysis of the high pressure phase diagram by Pistorius [36], a slope $\mathrm{dT} / \mathrm{dP}^{1 / 4} 24 \mathrm{~K} \mathrm{GPa}^{1}$ for the orthorhombic-to-hexagonal transition was obtained. The volume change was deduced to be $\mathrm{DV}^{1 / 4} 0.4 \mathrm{~cm}^{3} \mathrm{~mol}{ }^{1}$. The author deduced a value of entropy of transition $\mathrm{D}_{\mathrm{trs}} \mathrm{S}^{1} / 416.5 \mathrm{~J} \mathrm{~K}{ }^{1} \mathrm{~mol}$ 1. With the assump-tion that $\mathrm{D}_{\mathrm{trs}} \mathrm{S}$ is approximately constant along the transition line, the author found (DV) $)_{\mathrm{P}}^{1 / 4} 0^{1 / 4} 0.36 \mathrm{~cm}^{3} \mathrm{~mol}^{1}$, a value the author said "in fair agreement" with the value DV1/4 $0.970 .5 \mathrm{~cm}^{3} \mathrm{~mol}^{1}$ obtained by X-Ray Diffraction (XRD) pattern indexing. From the values of $\mathrm{D}_{\text {trs }} \mathrm{S}$ and $\mathrm{T}_{\text {trs }}$ given by Pistorius [36], the enthalpy of phase transition can be deduced as $\mathrm{D}_{\mathrm{trs}} \mathrm{H}^{1 / 46.303 \mathrm{~kJ} \text { mol }}{ }^{1}$. The enthalpy of the phase transition was also determined by Gorbunov et al. [17] as a sum of two values obtained from calorimetric peaks: $\mathrm{D}_{\text {trs }} \mathrm{H}^{1 / 41.17470 .069 p 5.05570 .0151 / 46.22970 .084}$ $\mathrm{kJ}$ mol ${ }^{1}$. The entropy of the transition was determined graphically by Gorbunov et al. [17] integrating the values of $\mathrm{C}_{\mathrm{p}, \mathrm{m}} / \mathrm{T}$ obtained with DSC measurements for (i) the unusual increase before the transition peak and (ii) the main transition peak. The entropy value was given as a sum of obtained values:

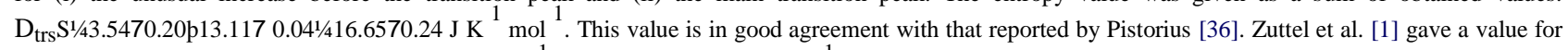
the enthalpy of transformation $\mathrm{D}_{\mathrm{trs}} \mathrm{H}^{1} / 44.18 \mathrm{~kJ}$ mol ${ }^{1}$, which is about $2 \mathrm{~kJ}$ mol ${ }^{1}$ lower than the value obtained by Gorbunov et al. [17]. Using ab-initio molecular dynamics approach, Zarkevich et al. [38] provided a value for the enthalpy of the transition of $\mathrm{D}_{\text {trs }} \mathrm{H}^{1 / 44} .6 \mathrm{~kJ}$ mol ${ }^{1}$ by considering boron relaxation, in good agree-ment with the value given by Zuttel et al. [1].

As summarized in Table 2, the value of the enthalpy of transition, based on the average of selected data reported in literature, is $\mathrm{D}_{\mathrm{trs}} \mathrm{H}^{1 / 45.370 .9} \mathrm{~kJ}$ $\mathrm{mol}^{1}$. From selected values of temperature and enthalpy of transition, $\mathrm{D}_{\mathrm{trs}} \mathrm{S}^{1 / 41472} \mathrm{~J} \mathrm{~K}{ }^{1}$ mol ${ }^{1}$ has been obtained.

\section{3. $\mathrm{LiBH}_{4}$ liquid state}

\subsubsection{Melting temperature}

Schlesinger and Brown in 1940, when preparing $\mathrm{LiBH}_{4}$ from diborane and ethyl-lithium, identified the melting temperature $\left(\mathrm{T}_{\mathrm{m}}\right)$ under static vacuum in the range 548-553 K, accompanied with a slight $\mathrm{H}_{2}$ release [39]. Fedneva et al. [35] reported DTA measurements on $\mathrm{LiBH}_{4}$ under hydrogen flow. They observed the melting of the compound in the $541-559 \mathrm{~K}$ temperature range, the variation being probably related to a $\mathrm{H}_{2}$ 
evolution. Pistorius [36] obtained $\mathrm{T}_{\mathrm{m}}{ }^{1} / 4588 \mathrm{~K}$ by extrapolation of data from high pressure down to atmospheric pressure. Due to the high pressure used in the experiments, he did not report any hydrogen release at melting. Stasinevich and Egorenko [16] found $\mathrm{T}_{\mathrm{m}}$ slightly increasing in the 551$555 \mathrm{~K}$ temperature range as a function of hydrogen pressure, being this range comparable to the measure-ments uncertainty. The reported average

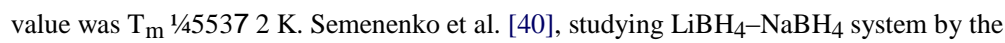

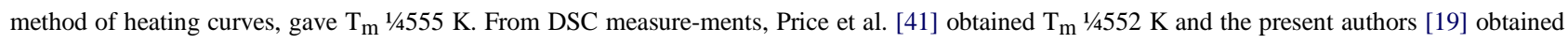
$\mathrm{T}_{\mathrm{m}} 1 / 4553 \mathrm{~K}$. In JANAF tables [22], the melting temperature for $\mathrm{LiBH}_{4}$ was estimated as $\mathrm{T}_{\mathrm{m}}{ }^{1 / 4750 \mathrm{~K}}$ by comparison with that of $\mathrm{NaBH}_{4}$.

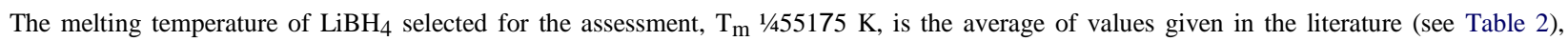
neglecting data given by Pistorious et al. [36] and by JANAF tables [22], which have not been obtained by experimental measurements.

\subsubsection{Enthalpy of melting}

Due to the high reactivity of the compound, few data have been reported in literature for the enthalpy of melting $\left(\mathrm{D}_{\mathrm{m}} \mathrm{H}\right)$ of $\mathrm{LiBH}_{4}$. In Ref. [41], a value of $\mathrm{D}_{\mathrm{m}} \mathrm{H}^{1 / 48.03} \mathrm{~kJ}$ mol ${ }^{1}$ has been obtained by thermal analysis. Zarkevich et al. [38], using an ab-initio molecular dynamics approach, calculated $\mathrm{D}_{\mathrm{m}} \mathrm{H}^{1 / 46.3 \mathrm{~kJ} \mathrm{~mol}}{ }^{1}$. In Ref. [1], a value of $\mathrm{D}_{\mathrm{m}} \mathrm{H}^{1 / 47.56} \mathrm{~kJ}$ mol ${ }^{1}$ has been reported, without a clear reference to the experimental or calculation technique used for the determination. The enthalpy of melting selected for the assessment was taken as the average of available values, corresponding to $\mathrm{D}_{\mathrm{m}} \mathrm{H}^{1 / 47.2} \mathrm{~kJ}$ mol ${ }^{1}$.

\subsubsection{Density}

The slope dT/dP at the melting in the diagram given by Pistorius [36] could be used to calculate the volume change at melting. By using the

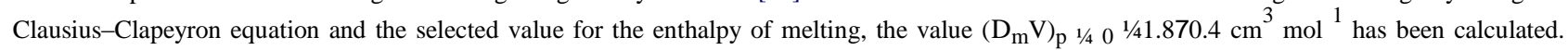
Using the volume of the unit cell of the hexagonal phase given by Filinchuk et al. [42] at $535 \mathrm{~K}$, the density of the liquid phase near the melting temperature can be estimated as $\mathrm{r}_{\text {liq }} 1 / 40.60370 .007 \mathrm{~g} \mathrm{~cm}^{3}$.

\section{4. $\mathrm{LiBH}_{4}$ thermal decomposition}

The compound synthesized by Schlesinger and Brown [39] had the chemical formula $\mathrm{Li}_{0.99} \mathrm{~B}_{1.02} \mathrm{H}_{3.8}$. When the sample was main-tained at 553 $\mathrm{K}$ for $10 \mathrm{~h}$ under primary vacuum, a release of $62.5 \%$ of $\mathrm{H}_{2}$ available in the compound was observed. The assumed decomposition reaction was at that time

$\mathrm{LiBH}_{4}$ ðsP-LiBðsP $\mathrm{p} 2 \mathrm{H}_{2}$ ðgP

ð2Р

Smith and Bass [29] calculated, on the basis of the enthalpy of formation determined by reaction (1), the heat of decomposition of several borohydrides and alanates according to the following reaction, with $\mathrm{X}^{1} / 4 \mathrm{Li}, \mathrm{Na}, \mathrm{K}$ and $\mathrm{M}^{1} / 4 \mathrm{~B}$, $\mathrm{Al}$

$\mathrm{XMH}_{4}$ ðcР-ХНðсР рMðсР $\mathrm{p}^{\frac{3}{2}}{ }_{2} \mathrm{H}_{2}$ ðgP

ðз

where (c) stands for condensed phase (i.e. solid or liquid) and

(g) for the gas phase. The estimated value for $\mathrm{LiBH}_{4}$ was equal to $103.4 \mathrm{~kJ} \mathrm{~mol}{ }^{1}$.

Fedneva et al. [35] detected by thermal analysis a main event at $653 \mathrm{~K}$ and a smaller one in the $756-765 \mathrm{~K}$ temperature range, associated to the delivering of about $80 \%$ of hydrogen available in the compound. Both signals were attributed to the thermal decom-position of the compound, without mentioning the decomposition products. It is worth noting that melting was accompanied by the delivering of about $2 \%$ of the hydrogen in the compound.

Stasinevich and Egorenko [16] observed the thermal decomposi-tion of $\mathrm{LiBH}_{4}$ by DTA at different hydrogen pressures (from 1.0133 bar to 10.133 bar). The decomposition temperature was observed to be dependent on hydrogen pressure, but a clear indication of decom-position products was not provided. The authors compared experi-mental results with a decomposition reaction according to

$\mathrm{LiBH}_{4}$ ðlP-LiHðsP pBðsP $\mathrm{p}^{\underline{3}}{ }_{2} \mathrm{H}_{2}$ ðgP

ð4P

where (1) and (s) stands for liquid and solid phases, respectively. The GFE of reaction (4) was given as $103.40 .150 \mathrm{~T} \mathrm{~kJ} \mathrm{~mol}^{1}$, whereas the GFE for the decomposition reaction into the pure components was reported as $194.10 .219 \mathrm{~T} \mathrm{~kJ} \mathrm{~mol}^{1}$. On the basis of experi-mental results, a thermal decomposition of $\mathrm{LiBH}_{4}$ via reaction (4) was claimed by the authors.

A DTA analysis of thermal decomposition of $\mathrm{LiBH}_{4}$ was reported in Ref. [43], where a small release of hydrogen $(0.3 \mathrm{wt} \%)$ in the $373-473 \mathrm{~K}$ temperature range was evidenced. No desorption of hydrogen was observed at melting, but a significant hydrogen delivering was detected starting at $593 \mathrm{~K}$. On the basis of the amount of delivered hydrogen, the formation of a product with nominal composition $\mathrm{LiBH}_{2}$ was claimed. When catalyzed with $\mathrm{SiO}_{2}, \mathrm{LiBH}_{2}$ was reported to transform into $\mathrm{LiH}$ and $\mathrm{B}$, with further hydrogen delivering.

A careful analysis of thermal decomposition of $\mathrm{LiBH}_{4}$ has been carried out by Mauron et al. [44] using dynamic Pressure- CompositionTemperature (PCT) and Thermal-Programmed-Desorption (TPD) measurements. $\mathrm{LiH}$ was observed as a decom-position product, so $\mathrm{LiBH}_{4}$ was supposed to decompose following reaction (4). According to the Van't Hoff equation, thermody-namic quantities were determined for the hydrogen desorption and values equal to $111 \mathrm{~kJ} \mathrm{~mol}{ }^{1}$ and $172 \mathrm{~J} \mathrm{~K}^{1} \mathrm{~mol}^{1}$ were given for the enthalpy and entropy of reaction, respectively. Even if the points obtained at high temperatures were well-located on a straight line in the Van ${ }^{0} \mathrm{t}$ Hoff plot, the authors observed that it cannot be excluded that the 
equilibrium was not fully reached during the experiments. In fact, at the lowest temperature (686 K), the experimental point appeared out of the fitting line.

Price et al. [41], on the basis of a study on the decomposition pathways of $\mathrm{LiBD}_{4}-\mathrm{MgD}_{2}$ multicomponent systems investigated by in-situ neutron diffraction, calculated an enthalpy and entropy of reaction (4) equal to $87.9 \mathrm{~kJ}$ mol ${ }^{1}$ and $120.1 \mathrm{~J} \mathrm{~K}^{1}$ mol ${ }^{1}$, respectively.

The heat of decomposition reaction of orthorhombic $\mathrm{LiBH}_{4}$ into $\mathrm{LiHpBp}_{2} / 2 \mathrm{H}_{2}$ at $0 \mathrm{~K}$ was estimated by Miwa et al. [23] by ab-initio calculations. A value of $112 \mathrm{~kJ} \mathrm{~mol}^{1}$ was reported, which turns into $150 \mathrm{~kJ}$ mol ${ }^{1}$ if Zero Point Energy (ZPE) is not included. In the frame of a large analysis of possible thermal decomposition products, Ohba et al. [28] calculated by ab-initio methods the heat of the same reaction as $112.5 \mathrm{~kJ}$ mol 1 whereas, more recently, Ozolins et al. [45] calculated a value of $129 \mathrm{~kJ}$ mol ${ }^{1}$. Using a similar approach, Frankcombe and Kroes [27], calculated a value of 93.7 $\mathrm{kJ} \mathrm{mol}{ }^{1}$ at room temperature.

The presence of $\mathrm{Li}_{2} \mathrm{~B}_{12} \mathrm{H}_{12}$ phase in the products of thermal decomposition of $\mathrm{LiBH}_{4}$ has been claimed on the basis of ab-initio calculations [28,46] and it has been confirmed experimentally by Raman spectroscopy [46] and NMR [47]. This intermediate com-pound also occurs during dehydrogenation of $\mathrm{LiBH}_{4}$ nanoconfined in the aerogel [10]. A very low hydrogen desorption temperature (i.e. $305 \mathrm{~K}$ ) has been recently observed in nanostructured $\mathrm{LiBH}_{4}$ [11]. In this case, the formation of $\mathrm{Li}_{2} \mathrm{~B}_{12} \mathrm{H}_{12}$ was observed at $538 \mathrm{~K}$, and even lower temperatures. From the analysis of dehydrogenation process of the $\mathrm{LiBH}_{4} / \mathrm{MgH}_{2}$ system, it has been suggested that the formation of $\mathrm{Li}_{2} \mathrm{~B}_{12} \mathrm{H}_{12}$ phase as a product is hindered at pressures higher than 2.0 MPa [48]. The formation of $\mathrm{B}_{2} \mathrm{H}_{6}$ during dehydrogenation of $\mathrm{LiBH}_{4}$ has been also suggested [49,50], causing a loss of boron. The $\mathrm{Li}_{2} \mathrm{~B}_{12} \mathrm{H}_{12}$ formation in the desorption of $\mathrm{LiBH}_{4}$ has been explained as a result of reaction of diborane with $\mathrm{LiBH}_{4}$ [49].

Experimental thermodynamic data of reactions involving $\mathrm{Li}_{2} \mathrm{~B}_{12} \mathrm{H}_{12}$ phase are not available. Ab-initio calculations have been performed for the following decomposition reaction:

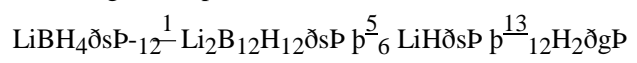
ð5

Ohba et al. [28] suggested a decomposition process of $\mathrm{LiBH}_{4}$ via reaction (5), giving an enthalpy equal to $60.7 \mathrm{~kJ}$ mol 1 .

Ozolins et al. [45] calculated at $300 \mathrm{~K}$ an enthalpy and entropy of reaction (5) equal to $48.1 \mathrm{~kJ}$ mol ${ }^{1}$ and $105.5 \mathrm{~J} \mathrm{~K}{ }^{1}$ mol ${ }^{1}$, respectively. More recently, Caputo and Zuttel ${ }^{*}[25]$ calculated a value of the enthalpy of reaction at $0 \mathrm{~K}$ equal to $60.7 \mathrm{~kJ}$ mol ${ }^{1}$, when $\mathrm{LiBH}_{4}$ is in the hexagonal structure.

$\mathrm{Li}_{2} \mathrm{~B}_{10} \mathrm{H}_{10}$ has been also reported as a possible product of the thermal decomposition reaction [28,49], but experimental ther-modynamic data about this compound are lacking. A value of enthalpy equal to $348 \mathrm{~kJ}$ mol ${ }^{1}$ was calculated for the $2 \mathrm{LiHp}^{10 \mathrm{Bp}} 4 \mathrm{H}_{2}-\mathrm{Li}_{2} \mathrm{~B}_{10} \mathrm{H}_{10}$ reaction by ab-initio methods [28], neglect-ing ZPE corrections.

\section{Thermodynamic modeling}

Thermodynamic modeling is based on a parametric description of the GFE, as a function of temperature and pressure, for $\mathrm{LiBH}_{4}$ compound and for possible decomposition products. All phases have been considered as stoichiometric compounds, i.e. with a fixed composition. The GFE functions for all phases have been defined in a wide temperature range, even in domains beyond the phase stability. No pressure dependence of the GFE has been considered for the condensed phases. For $\mathrm{LiBH}_{4}$, parameters have been deter-mined for orthorhombic, hexagonal and liquid phases. For the products of thermal decomposition, parameters have been taken from available databases [20]. For $\mathrm{Li}_{2} \mathrm{~B}_{12} \mathrm{H}_{12}$ and $\mathrm{Li}_{2} \mathrm{~B}_{10} \mathrm{H}_{10}$ phases, parameters were not available, so they have been determined as described below. Hydrogen has been described as an ideal gas phase, according to Ref. [20]. The Parrot module of the Thermocalc software [51,52] was used for the assessment.

\subsection{Assessment of Gibbs Free Energy functions}

In order to evaluate the temperature dependence of the GFE of condensed phases, the pure elements in their stable structure at $298.15 \mathrm{~K}$ under a pressure of 1 bar were chosen as a reference state (SER, Standard Element Reference) as recommended by SGTE (Scientific Group Thermodata Europe) [53].

The temperature dependence of the GFE of a compound (COMP) has been described with the following polynomial expression [12]:

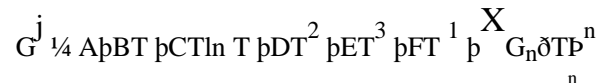

ð6Р

where $\mathrm{j}$ represents the phase and the parameters $\mathrm{A}-\mathrm{G}_{\mathrm{n}}$ are optimized on the basis of the available experimental or computed data. If necessary, different set of parameters have been used to describe the same phase in different temperature ranges. When thermodynamic data are available at low temperatures, a more complex expression of GFE, based on the Einstein model for the molar heat capacity [54], has been used.

The calculation of the enthalpy $(\mathrm{H})$, entropy $(\mathrm{S})$ and free energy $(\mathrm{G})$ functions is based on the integration of the molar heat capacity, according to the following equations:

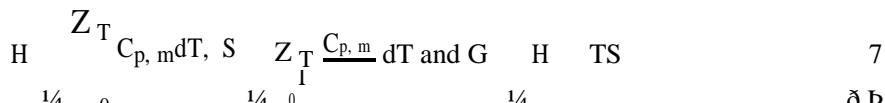


Starting from selected values for the standard heat of forma-tion $\left(\mathrm{D}_{\mathrm{f}} \mathrm{H}_{298}{ }^{\mathrm{j}}\right)$ and standard entropy $\left(\mathrm{S}_{298}{ }^{\mathrm{1}}\right)$ of the orthorhombic phase at 298.15 $\mathrm{K}, \mathrm{H}$ and $\mathrm{S}$ of each phase are deduced as a function of temperature, knowing the enthalpy and entropy of the phase transformations, according to

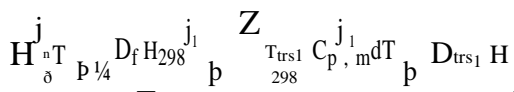

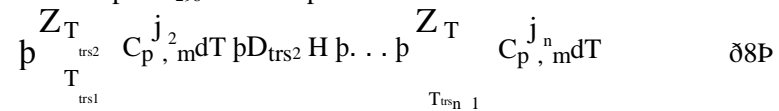

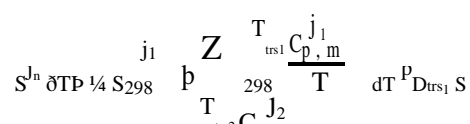

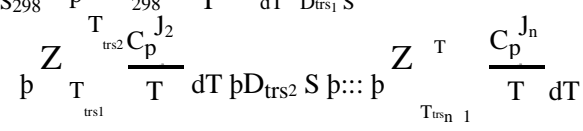

where $D_{\text {trsn }} H, D_{\text {trsn }} S$ and $T_{\text {trsn }}$ are the enthalpy, entropy and temperature for the phase transition n, respectively. The quan-tities used for the calculation of GFE functions for $\mathrm{LiBH}_{4}$ phases are taken from selected values collected in Table A2 in Appendix: Supplementary data.

For each phase, different parameters for GFE were evaluated for different temperature ranges identified according to transition temperatures. The GFE parameters for each phase were assessed so that, outside the temperature range of stability, the molar heat capacity approaches that of the stable phase [55]. It should be noticed that this approach, suggested by SGTE [53], is not based on physical models, but it guarantees that extrapolations outside the phase stability range yield a reasonable description of GFE. According to this approach, an unreasonable step in the $\mathrm{C}_{\mathrm{p}, \mathrm{m}}$ function of each phase at the equilibrium transition temperature is avoided. However, in order to allow a smooth change of the $\mathrm{C}_{\mathrm{p}, \mathrm{m}}$ at the transition temperature high order terms $\left(\mathrm{T}^{9}\right.$ and $\mathrm{T}^{7}$ ) have been introduced in the GFE expression for the temperature ranges where each phase is not stable. The contributions of the high order terms to the polynomial expression of GFE are rather lower than those related to low order terms.

\subsubsection{Orthorhombic phase}

For this phase, $C_{p, m}$ data $[15,17,19]$ are available from low temperature up to the phase transition. So, two temperature ranges from $0 \mathrm{~K}$ to $383 \mathrm{~K}$ and above $383 \mathrm{~K}$ were identified. In the first temperature range, the Einstein model [54] was used to describe the GFE. In the high temperature range, where the orthorhombic phase is not stable, the GFE is described so that the constant molar heat capacity of the liquid (see below) is approached gradually according to

$\mathrm{LiBH}_{4} \mathrm{G}^{\text {Ortho }}$ ðT $4383 \mathrm{KP}^{1 / 4} \mathrm{LiBH}_{4} \mathrm{G}^{\text {Liquid }}{ }_{\text {pApBT } \mathrm{pCT}^{9}}^{9}$ ð10P

where the parameters $\mathrm{A}, \mathrm{B}$ and $\mathrm{C}$ have been evaluated in order to have the continuity of the enthalpy, entropy and molar heat capacity of the orthorhombic phase at $383 \mathrm{~K}$. The term $\mathrm{CT}^{9}$ brings gradually the $\mathrm{C}_{\mathrm{p}, \mathrm{m}}$ of the orthorhombic phase to that of the liquid phase.

\subsubsection{Hexagonal phase}

Three temperature ranges were identified for the hexagonal phase: $0-383 \mathrm{~K}, 383-551 \mathrm{~K}$ and above $551 \mathrm{~K}$. In the $383-551 \mathrm{~K}$ temperature range, where the hexagonal phase is stable, the GFE function has been described with Eq. (6) on the basis of available $\mathrm{C}_{\mathrm{p}, \mathrm{m}}$ data for this phase [19], of selected values for the enthalpy and entropy of transition and of the thermodynamic function of the orthorhombic phase, as described above in Eqs. (8) and (9).

In the low temperature range $(0-383 \mathrm{~K})$, where the hexagonal phase is not stable, the GFE function has been described so that the molar heat capacity of the hexagonal phase reaches gradually that of the orthorhombic phase, according to the equation

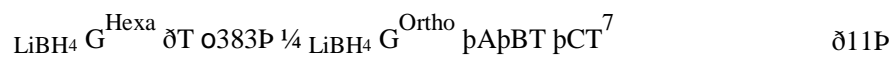

Even in this case, A, B and C parameters have been evaluated in order to have the continuity of the enthalpy, entropy and molar heat capacity of the hexagonal phase at $383 \mathrm{~K}$.

For the high temperature range, above melting temperature (T4551 K), the same approach described before has been fol-lowed, so that the same polynomial expression of Eq. (10) has been adopted for the description of GFE.

\subsubsection{Liquid phase}

The GFE for the liquid phase has been described with two set of parameters, valid in the low temperature range of liquid undercooling (0-551 K) and above the melting temperature $(551 \mathrm{~K})$, where the liquid phase is stable. For the latter tempera-ture range, due to the absence of data, a constant molar heat capacity was considered, so that the GFE has been described with the following function:

$\mathrm{LiBH}_{4} \mathrm{G}^{\text {Liquid }}{ }_{1 / 4}$ ApBT pCTlnðTP

where the selected values for the enthalpy and entropy of melting were used to determine the parameters $\mathrm{A}$ and $\mathrm{B}$ of this equation and the $\mathrm{C}$ parameter has been set on the basis of the estimated molar heat capacity of the liquid phase [19]. 
The GFE of the liquid phase in the low temperature range $(0-551 \mathrm{~K})$ has been described with an equation similar to Eq. (11), once again driving the molar heat capacity of the liquid phase toward that of the orthorhombic phase at low temperatures and checking the continuity of the enthalpy, entropy and molar heat capacity of the liquid phase at the melting temperature $(551 \mathrm{~K})$.

\subsection{4. $\mathrm{Li}_{2} \mathrm{~B}_{12} \mathrm{H}_{12}$ and $\mathrm{Li}_{2} \mathrm{~B}_{10} \mathrm{H}_{10}$ phases}

Because $\mathrm{Li}_{2} \mathrm{~B}_{12} \mathrm{H}_{12}$ compound has been reported as a product of the thermal decomposition reaction $[28,46,47]$ but parameters for the description of its GFE are not available, a specific assess-ment of thermodynamic properties of this phase has been carried out. This phase has been treated as a stoichiometric phase, so that GFE has been described as

Li2 $\mathrm{B} 12 \mathrm{H}_{12} \mathrm{G}_{2} \frac{1 / 4}{12}{ }_{\mathrm{B}} \mathrm{G}^{\text {Rhombo }} \mathrm{p}_{\mathrm{H} 2} \mathrm{G}^{\mathrm{Gas}} \mathrm{p} 2_{\mathrm{Li}}{ }^{\mathrm{BCC}} \mathrm{pApBT}$ ð13P

The parameters $\mathrm{A}$ and $\mathrm{B}$ have been evaluated on the basis of the ab-initio calculated enthalpy and entropy reported in Ref. [45] for the following

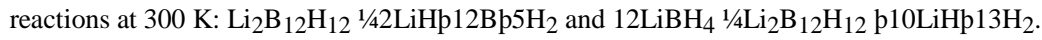

Similarly, for the $\mathrm{Li}_{2} \mathrm{~B}_{10} \mathrm{H}_{10}$ compound, the GFE has been described as:

Li2 $\mathrm{B} 10 \mathrm{H} 10 \mathrm{G}_{2}{ }^{1 / 4} 1_{10} \mathrm{BG}^{\text {Rhombo }}{ }_{\mathrm{p} 4} \mathrm{H}_{2} \mathrm{G}^{\mathrm{Gas}}{ }_{\mathrm{p} 2} \mathrm{LiHG}^{\mathrm{Cubic}}{ }_{\mathrm{pApBT}}$

The parameter A has been evaluated on the basis of the ab-initio calculations at $0 \mathrm{~K}$ reported in Ref. [28] and the para-meter B has been fixed on the basis of the entropy change from gaseous hydrogen state to solid hydride (i.e. $130 \mathrm{~J} \mathrm{~K}^{1} \mathrm{~mol}^{1}$ ).

GFE functions for ${ }_{\mathrm{B}} \mathrm{R}^{\mathrm{Rhombo}}, \mathrm{H}_{2} \mathrm{G}^{\mathrm{GaSH}_{2}}, \mathrm{G}^{\mathrm{cc}}$ and ${ }_{\mathrm{Li}} \mathrm{G}^{\mathrm{Cubic}}$ have been taken from Ref. [20].

\subsubsection{Assessment procedure}

In a preliminary assessment procedure, experimental data on thermal decomposition of liquid $\mathrm{LiBH}_{4}$ at different $\mathrm{H}_{2}$ pressures [16,44] were considered to evaluate the GFE of the liquid phase, assuming a full decomposition into $\mathrm{LiHpBp} 3 / 2 \mathrm{H}_{2}$ or $1 / 12 \mathrm{Li}_{2} \mathrm{~B}_{12} \mathrm{H}_{12} \mathrm{p} 5 / 6 \mathrm{LiHp} 13 / 12 \mathrm{H}_{2}$. Actually, a full decomposition into these products turned out to be not coherent with selected values for enthalpy end entropy of melting. This result suggests that the decomposition mechanism of liquid $\mathrm{LiBH}_{4}$ observed experimentally might be more complex than that described by reactions mentioned above. In fact, the DSC signal of Ref. [56] as well as the differential curve of the thermal desorption spectra reported in Ref. [1] show several peaks. So, thermal decomposi-tion data have not been considered for the assessment because equilibrium conditions were not guaranteed. Table 4 shows, for each phase and within the temperature range of validity, the assessed parameters for the GFE functions that have been deter-mined and used for the following calculations.

Table 4

Assessed Gibbs Free Energy functions of the $\mathrm{LiBH}_{4}$ condensed phases, $\mathrm{Li}_{2} \mathrm{~B}_{12} \mathrm{H}_{12}$ and $\mathrm{Li}_{2} \mathrm{~B}_{10} \mathrm{H}_{10}$, with their $\mathrm{T}$ range of validity.

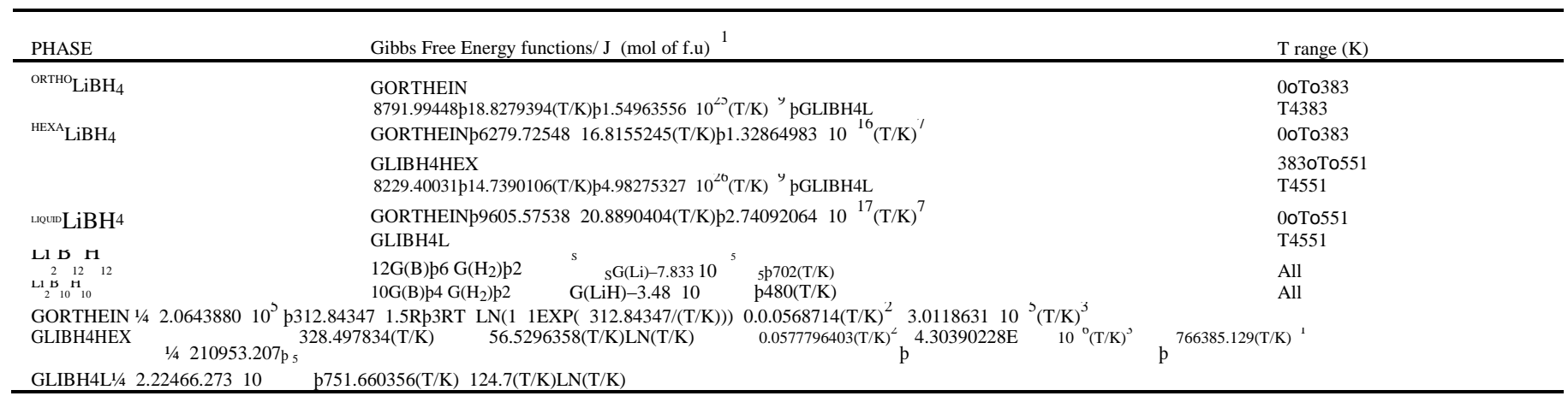
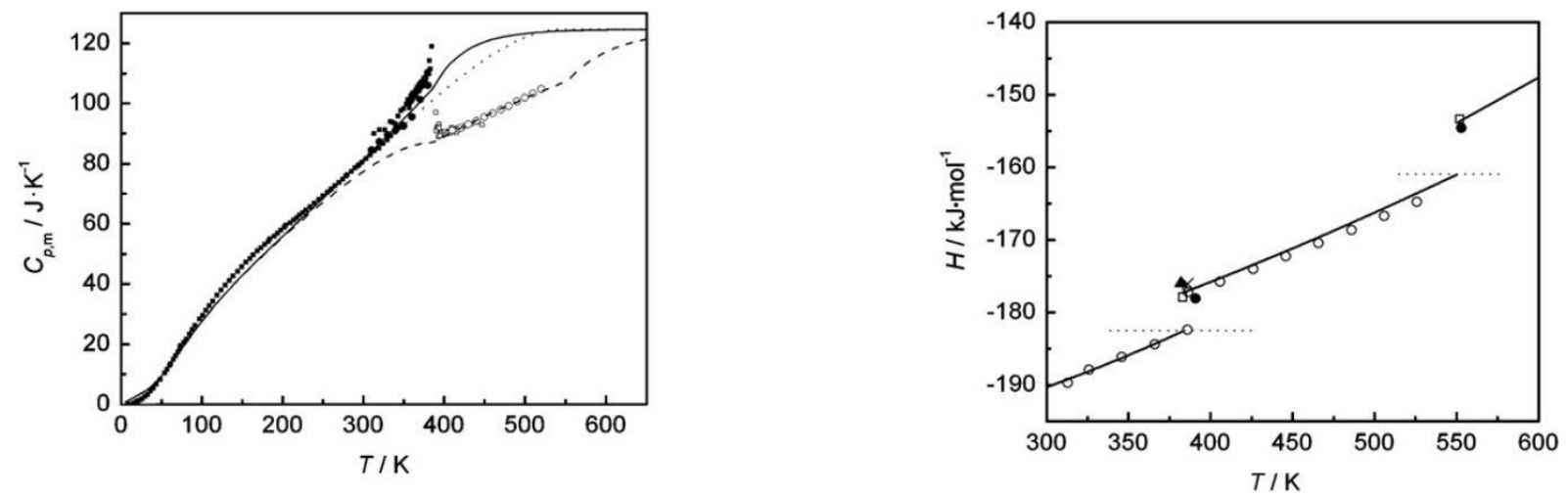
Fig. 1. Calculated molar heat capacity, $\mathrm{C}_{\mathrm{p}, \mathrm{m}}$, for $\mathrm{LiBH}_{4}$ : orthorhombic (continuous line -), hexagonal (dashed line $\longrightarrow$ ) and liquid (dotted line ) at different temperatures compared to experimental values from Ref. [17] (' filled squares for the orthorhombic phase, \& open squares for the hexagonal phase) and Ref. [19] (K filled circles for the orthorhombic phase, J open circles for the hexagonal phase).

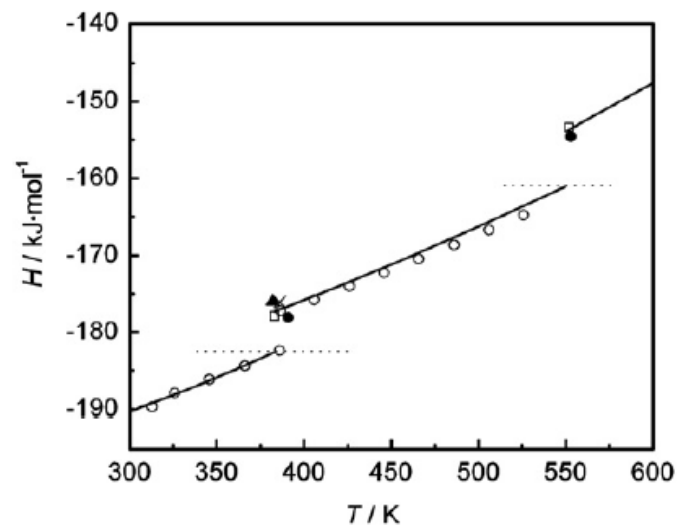

Fig. 2. Enthalpy ( $\mathrm{H}-\mathrm{H}^{\mathrm{SER}}$ ) as a function of temperature for the different phases of $\mathrm{LiBH}_{4}$ in the respective ranges of stability. Continuous line ( - ) shows the results of calculation. Experimental molar heat capacity values from Ref. [19] have been integrated with respect to temperature and are shown as open circles (J). Experimental enthalpies of phase transformations from Refs. [1] K, [17] , [36] m, [41] \& have been added for comparison to the values calculated at the temperature of phase transformations (horizontal dotted lines).

\section{Consistency of results and discussion}

The calculated molar heat capacity of the various phases of $\mathrm{LiBH}_{4}$ compared to experimental data $[17,19]$ are reported in Fig. 1. The agreement between experimental and calculated values for the solid phases is rather good in the whole tempera-ture range. At low temperatures (0-383 K), where the orthor-hombic phase is stable, the Einstein model appears suitable for the description of experimental data. In the 383-551 K tempera-ture range, where the hexagonal phase is stable, the molar heat capacity values are well described by the equation selected for this phase. Above the melting temperature $(551 \mathrm{~K})$, no experi-mental data are available, so a constant value of molar heat capacity is considered for the liquid phase, as estimated in Ref. [19]. It is worth noting that, outside the temperature range of stability, the molar heat capacity of metastable phases are merging the values of the stable phase, as described above. A comparison of obtained results with data available in the literature is reported in Figure A1 in Appendix: Supplementary data.

The enthalpy function of $\mathrm{LiBH}_{4}$ is presented in Fig. 2 as a function of temperature, taking into account the stable phase in various temperature ranges. The plot starts at $298.15 \mathrm{~K}$ at $190.46 \mathrm{~kJ} \mathrm{~mol}{ }^{1}$, corresponding to the selected value for the enthalpy of formation of $\mathrm{LiBH}_{4}$. Experimental molar heat capacity values taken from Ref. [19] have been integrated with respect to temperature and corresponding enthalpy values are shown as open circles. They fit well with the calculated enthalpy of $\mathrm{LiBH}_{4}$ at different temperatures. For comparison, existing experimental data of enthalpies of transformations (polymorphous transition and melting) have been reported in the figure at the

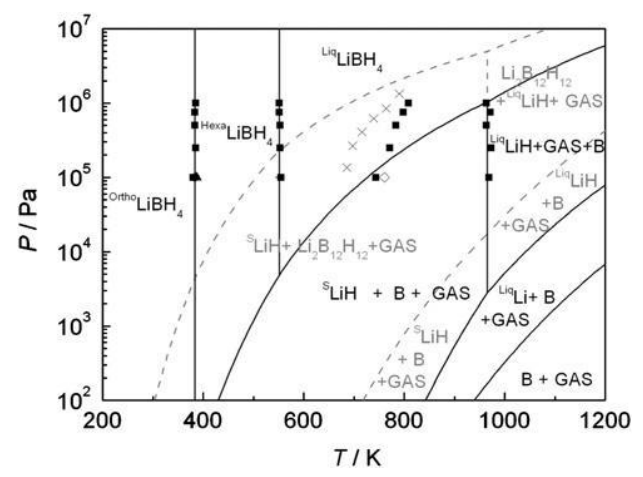

Fig. 3. Calculated $\mathrm{LiBH}_{4}$ phase diagram considering $\mathrm{Li}_{2} \mathrm{~B}_{12} \mathrm{H}_{12}$ and $\mathrm{Li}_{2} \mathrm{~B}_{10} \mathrm{H}_{10}$ compounds (dashed line $\longrightarrow$ ) or without considering $\mathrm{Li}_{2} \mathrm{~B}_{12} \mathrm{H}_{12}$ and $\mathrm{Li}_{2} \mathrm{~B}_{10} \mathrm{H}_{10}$ in the calculations (continuous line -). Experimental values of phase transitions from Refs. [16] ', [44] , [35] B, [19] m, [36] K, [18] J and [41] p are shown for comparison.

corresponding temperatures of transformations, by referring to the enthalpy of the stable phase at the same temperature (horizontal dotted lines). The calculated enthalpy variation at the phase transitions of $\mathrm{LiBH}_{4}$ are within error uncertainty of measurements, indicating a fairly good agreement between cal-culated and experimental values. 
Fig. 3 shows the calculated phases stability for $\mathrm{LiBH}_{4}$ as a function of $\mathrm{H}_{2}$ pressure and temperature. Vertical lines represent phase transitions involving only condensed phases, so that there
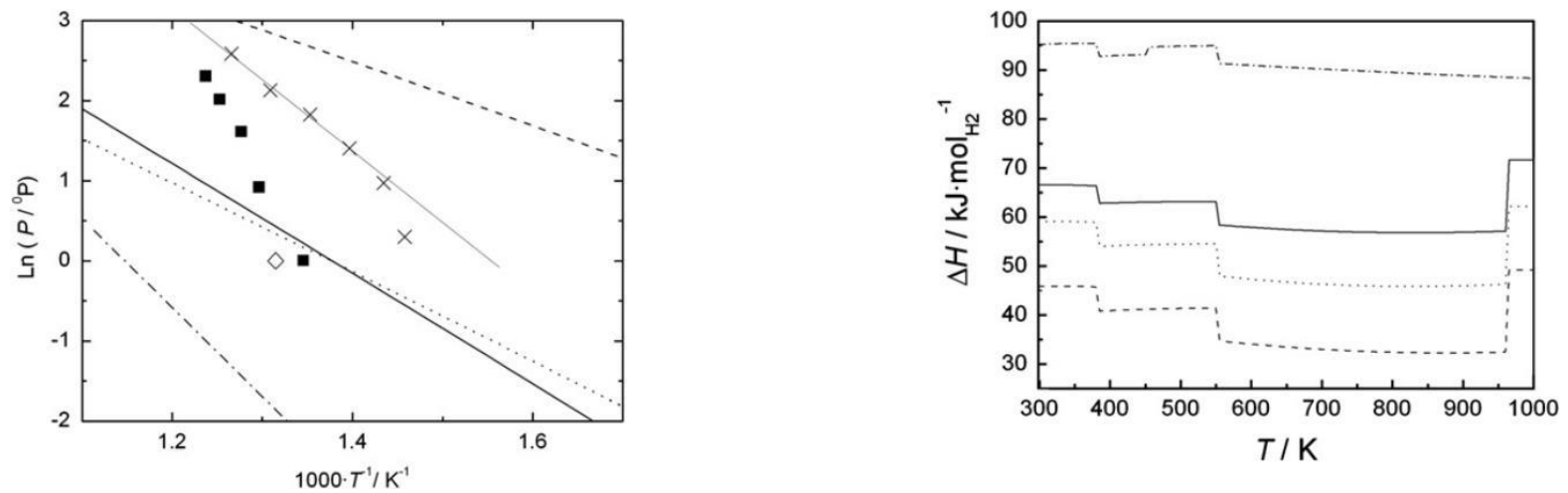

Fig. 4. Calculated Van't Hoff plot for possible $\mathrm{LiBH}_{4}$ decomposition reactions: $\mathrm{LiBH}_{4}-1 / 12 \quad \mathrm{Li}_{2} \mathrm{~B}_{12} \mathrm{H}_{12}$ p5/6 $\mathrm{LiHp} 13 / 12 \mathrm{H}_{2}$ (dashed line $\longrightarrow$ ); $\mathrm{LiBH}_{4}-1 / 10 \mathrm{Li}_{2} \mathrm{~B} 10 \mathrm{H}_{10} \mathrm{p} 4 / 5$

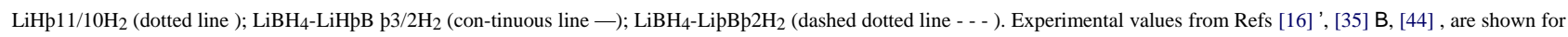
comparison. The Van't Hoff plot reported in [44] is also shown as a thin line.

is no pressure dependence for the temperature of transformation. On the contrary, phase transformations related to $\mathrm{H}_{2}$ evolution are represented as sloped curves, because of the pressure-dependence of the temperature of transformation. In order to check the reliability of calculated phase diagram, experimental data on phase transformations are added to the plot. A rather good agreement can be observed for polymorphous transforma-tion and melting.

Concerning thermal decomposition reactions, the comparison between calculated and experimental results is strongly related to a clear description of reaction products. In order to consider different thermal decomposition reactions of $\mathrm{LiBH}_{4}$, stable and metastable phase diagrams have been calculated. In particular, dashed lines in Fig. 3 consider the stable reaction products, i.e. 1/12 $\mathrm{Li}_{2} \mathrm{~B}_{12} \mathrm{H}_{12}$ p5/6 LiHp13/12 $\mathrm{H}_{2}$. In this case, $\mathrm{Li}_{2} \mathrm{~B}_{12} \mathrm{H}_{12}$ is found to be stable in a wide range of temperature and pressures. If the formation of $\mathrm{Li}_{2} \mathrm{~B}_{12} \mathrm{H}_{12}$ and $\mathrm{Li}_{2} \mathrm{~B}_{10} \mathrm{H}_{10}$ phases is considered kine-tically hindered, they can be rejected from the calculations (continuous lines in Fig. 3), so that the products of the decom-position reaction become $\mathrm{LiHpBp} 3 / 2 \mathrm{H}_{2}$. In order to understand the behavior of real systems during thermal decomposition experiments, the following reactions have been studied

$\mathrm{LiBH}_{4}-1=12 \mathrm{Li}_{2} \mathrm{~B}_{12} \mathrm{H}_{12}$ p5=6 LiHp13=12 $\mathrm{H}_{2}$

$\mathrm{LiBH}_{4}-1=10 \mathrm{Li}_{2} \mathrm{~B}_{10} \mathrm{H}_{10} \mathrm{p} 4=5 \mathrm{LiHp} 11=10 \mathrm{H}_{2}$

$\mathrm{LiBH}_{4}-\mathrm{LiHpBp} 3=2 \mathrm{H}_{2}$

$\mathrm{LiBH}_{4}-\mathrm{LipBp} 2 \mathrm{H}_{2}$

The Van't Hoff plot for these decomposition reactions has been calculated and the results are shown in Fig. 4, together with available experimental data. At ambient pressure, the results of Fedneva et al. [35] and of Stasinevich and Egorenko [16] lie far away from the calculated line for reaction (15). They fairly agree with the calculated metastable decomposition to LiH (reaction (17)), but, when the pressure and temperature are increased, the agreement becomes scarce. This result suggests that during these experiments, as also reported by the authors [16], equilibrium conditions were not fulfilled. Moreover, the experimental results obtained by Mauron et al. [44] show a limited agreement with calculations, approaching the stable decomposition reaction (15) at the highest pressure (about $10^{6} \mathrm{~Pa}$ ) and temperature, but tend to metastable reaction (17) at ambient pressure and lower temperatures. In fact, in a recently published paper from the

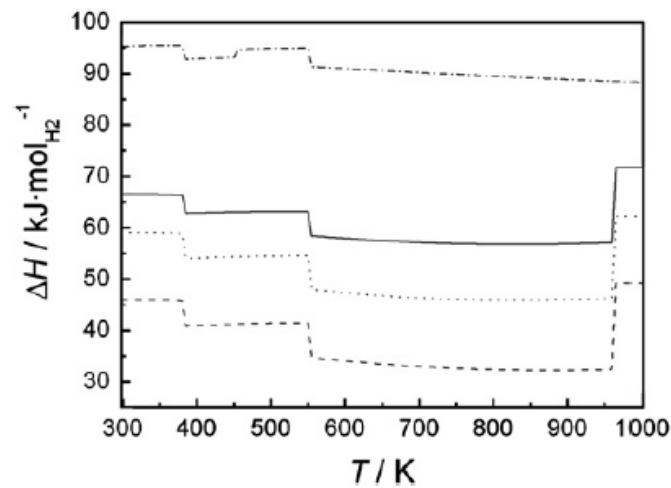


Fig. 5. Calculated reaction enthalpy for possible $\mathrm{LiBH}_{4}$ decomposition reactions: $\mathrm{LiBH}_{4}-1 / 12 \quad \mathrm{Li}_{2} \mathrm{~B}_{12} \mathrm{H}_{12} \mathrm{p} 5 / 6 \quad \mathrm{LiHp}_{13} / 12 \mathrm{H}_{2}$ (dashed line $\longrightarrow$ ); $\mathrm{LiBH}_{4}-1 / 10 \mathrm{Li}_{2} \mathrm{~B} 10 \mathrm{H}_{10}$ p4/5 LiHp11/10H (dotted line ); $\mathrm{LiBH}_{4}-\mathrm{LiHpBp}_{2} / 2 \mathrm{H}_{2}$ (con-tinuous line -); $\mathrm{LiBH}_{4}-\mathrm{LipBp}_{2} \mathrm{H}_{2}$ (dashed dotted line - - - ).

same group [57], it is suggested that decomposition according to reaction (17) seems kinetically favoured, whereas reaction (15) is kinetically hindered. In fact, in order to promote reaction (15) and overcome the kinetic barrier, the temperature has to be signifi-cantly increased. So, even if some uncertainties are related to the thermodynamic stability of $\mathrm{Li}_{2} \mathrm{~B}_{12} \mathrm{H}_{12}$, because assessed para-meters are based only on ab-initio calculations [45], it appears that its formation, even if thermodynamically favoured, must be kinetically hindered.

Since the calculated Van't Hoff plots for various decomposition reactions lie away from the experimental results [16,35,44], it is unlikely that single decomposition reactions take place during experiments. In fact, even if traces of $\mathrm{Li}_{2} \mathrm{~B}_{12} \mathrm{H}_{12}$ have been detected in the decomposition products according to reaction (15) [28,46,47], the metastable decomposition reaction (17) is also present [44]. The decomposition reaction (16), leading to $\mathrm{Li}_{2} \mathrm{~B}_{10} \mathrm{H}_{10}$, is less favoured than reaction (15), but it is close to reaction (17). As a result, as shown in Figure A4 of Appendix: Supplementary data, if the formation of $\mathrm{Li}_{2} \mathrm{~B}_{12} \mathrm{H}_{12}$ is kinetically hindered, $\mathrm{Li}_{2} \mathrm{~B}_{10} \mathrm{H}_{10}$ should be the decomposition product at low temperatures, but when the temperature is increased it should be replaced by $\mathrm{LiH}$.

According to the stable phase diagram (Fig. 3), at 1 bar $\mathrm{H}_{2}$ pressure, $\mathrm{Li}_{2} \mathrm{~B}_{12} \mathrm{H}_{12}$ should be stable above $500 \mathrm{~K}$ and a driving force for reaction (15) should be present above that temperature. This driving force could explain the hydrogen transport detected in $\mathrm{LiBH}_{4}$ below the melting temperature[58], as well as the small hydrogen release detected during melting $[35,39,46]$. In fact, at these temperatures, there should be no driving force for the decomposition into $\mathrm{LiH}$ according to reaction (17) pathway, so that release of $\mathrm{H}_{2}$ should not be observed.

Table 3 summarizes the enthalpy and entropy values collected from the literature for selected decomposition reactions. For com-parison, Fig. 5 shows the enthalpy of decomposition reactions, calculated as a function of temperature at $1 \mathrm{bar}_{2}$. Discontinuities are due to phase transitions of compounds involved in the reactions. As a general trend, the enthalpy of reactions initially decreases when increasing the temperature, because of the polymorphous transition and melting of the reactant $\left(\mathrm{LiBH}_{4}\right)$. The increase in enthalpy observed at $961 \mathrm{~K}$ is due to melting of $\mathrm{LiH}$, one of the products of reactions $(15,16$ and 17). The value of the enthalpy of reaction (18) at $298 \mathrm{~K}$ correctly reproduces the value given in JANAF tables [22]. On the other hand, around $700 \mathrm{~K}$, the enthalpy calcu-lated for reaction (17) is quite different from the value reported in Ref. [44]. It is worth noting that a wide discrepancy is reported for the enthalpy of this reaction: as summarized in Table 3, considering both experimental and calculated values, it varies from 52 to $75 \mathrm{~kJ} \mathrm{~mol}_{\mathrm{H} 2}{ }^{1}$. In fact, even if several papers attributed the thermal

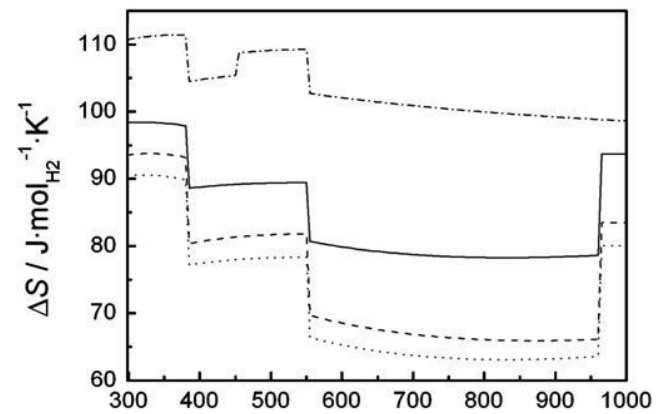

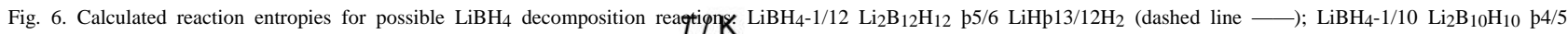
LiHp1 1/10H 2 (dotted line ); $\mathrm{LiBH}_{4}-\mathrm{LiHpBp}_{3} / 2 \mathrm{H}_{2}$ (con-tinuous line -); $\mathrm{LiBH}_{4}-\mathrm{LipBp}_{2} \mathrm{H}_{2}$ (dashed dotted line - - - ).

decomposition of $\mathrm{LiBH}_{4}$ to this reaction pathway, a clear determina-tion of decomposition products is often missing.

Fig. 6 shows the calculated entropy at 1 bar $\mathrm{H}_{2}$ as a function of temperature for various decomposition reactions. Similarly to the enthalpy behavior reported in Fig. 5, the effect of phase transi-tions of the compounds involved in the reactions turns out as a decrease in the entropy of dehydrogenation reaction when $\mathrm{LiBH}_{4}$ undergoes a phase transition or as an increase in the case of a phase transformation of products. Close to room temperature, an

whereas lower values, between 90 and $100 \mathrm{~J} \mathrm{~K}^{1} \mathrm{~mol}_{\mathrm{H} 2}{ }^{1}$, have been obtained for other decomposition reactions. This result can be explained considering the high entropy of dehydrogenation for

products of these decomposition reactions. 
A new assessment of thermodynamic properties of $\mathrm{LiBH}_{4}$ has been performed after a critical evaluation of available thermody-namic data. This work is an update of JANAF thermochemical tables for $\mathrm{LiBH}_{4}$, which were not reviewed since 1998. A selection of values for thermodynamic properties of condensed phases (orthor-hombic, hexagonal and liquid) of $\mathrm{LiBH}_{4}$ have been collected. In particular, literature data for the heat of formation of the compound have been reviewed and the value of $190.4670 .21 \mathrm{~kJ}$ mol ${ }^{1}$ given in JANAF tables [22] has been confirmed. New analytical functions for the Gibbs Free Energy of the condensed phases have been obtained, also in the temperature range outside their stability, and a pressure-temperature phase diagram has been calculated. Possible thermal decomposition reactions of $\mathrm{LiBH}_{4}$ have been analyzed, evidencing that the direct decomposition into $\mathrm{LiH}$ and boron seems kinetically favoured, whereas the stable decomposi-tion reaction via $\mathrm{Li}_{2} \mathrm{~B}_{12} \mathrm{H}_{12}$ is $\mathrm{kinetically}_{1}$ hindered. The new thermo-dynamic functions may provide relevant insights into the study of $\mathrm{LiBH}_{4}$ for hydrogen storage purposes. In particular, the developed thermodynamic database for $\mathrm{LiBH}_{4}$ allows to display phase trans-formations in working conditions (i.e. pressure and temperature) and to show thermodynamically favoured decomposition products, enabling to distinguish between thermodynamically or kinetically driven reactions.

\section{Acknowledgments}

This work is supported by the European Commission under COSY (MRTN-CT-2006-035366) and FLYHY (NMP-2008-261/226943) projects. Special thanks are due to Christian Chatillon for helpful discussions and the preliminary critical reading of the manuscript and to Evelyne Fischer for help in using softwares available at Thermodata, Grenoble.

\section{References}

[1] A. Zuttel," A. Borgschulte, S.-I. Orimo, Tetrahydroborates as new hydrogen storage materials, Scr. Mater. 56 (2007) $823-828$.

[2] C. Li, P. Peng, D.W. Zhou, L. Wan, Research progress in $\mathrm{LiBH}_{4}$ for hydrogen storage: a review, Int. J. Hydrogen Energy 36 (2011) 14512-14526.

[3] L.H. Rude, E. Groppo, L.M. Arnbjerg, D.B. Ravnsbaek, R.A. Malmkjaer, Y. Filinchuk, M. Baricco, F. Besenbacher, T.R. Jensen, Iodide substitution in lithium borohydride, $\mathrm{LiBH}_{4}-\mathrm{LiI}, \mathrm{J}$. Alloys Compd. 509 (2011) 8299-8305.

[4] Y. Nakamori, S.I. Orimo, Destabilization of Li-based complex hydrides, J. Alloys Compd. 370 (2004) 271-275.

[5] L.H. Rude, T.K. Nielsen, D.B. Ravnsbaek, U. Bosenberg, M.B. Ley, B. Richter, L.M. Arnbjerg, M. Dornheim, Y. Filinchuk, F. Besenbacher, T.R. Jensen, Tailor-ing properties of borohydrides for hydrogen storage: a review, Phys. Status Solidi A: Appl. Mater. Sci. 208 (2011) 1754-1773.

[6] L.H. Rude, O. Zavorotynska, L.M. Arnbjerg, D.B. Ravnsbaek, R.A. Malmkjaer,

H. Grove, B.C. Hauback, M. Baricco, Y. Filinchuk, F. Besenbacher, T.R. Jensen, Bromide substitution in lithium borohydride, LiBH4-LiBr, Int. J. Hydrogen Energy 36 (2011) $15664-15672$.

[7] H.W. Li, Y.G. Yan, S. Orimo, A. Zuttel, C.M. Jensen, Recent progress in metal borohydrides for hydrogen storage, Energies 4 (2011) $185-214$.

[8] J.J. Vajo, S.L. Skeith, F. Mertens, Reversible storage of hydrogen in destabilized LiBH4, J. Phys. Chem. B 109 (2005) 3719-3722.

[9] R.A. Varin, T. Czujko, Z.S. Wronski, Nanomaterials for solid state hydrogen storage, Springer US, Boston, MA, 2009

[10] J.J. Vajo, Influence of nano-confinement on the thermodynamics and dehy-drogenation kinetics of metal hydrides, Curr. Opin. Solid State Mater. Sci. 15 (2011) 52-61.

[11] X.F. Wan, L.L. Shaw, Novel dehydrogenation properties derived from nanos-cale $\mathrm{LiBH}_{4}$, Acta Mater. 59 (2011) $4606-4615$.

[12] H.L. Lukas, S.G. Fries, B. Sundman, Computational Thermodynamics, Cam-bridge University Press, Newyork, USA, 2007.

[13] Y.W. Cho, J.H. Shim, B.J. Lee, Thermal destabilization of binary and complex metal hydrides by chemical reaction: a thermodynamic analysis, Calphad: Comput. Coupling Phase Diagrams Thermochem. 30 (2006) 65-69.

[14] W.D. Davis, L.S. Mason, G. Stegeman, The heats of formation of sodium borohydride, lithium borohydride and lithium aluminum hydride, J. Am. Chem. Soc. 71 (1949) $2775-$ 2781.

[15] N.C. Hallett, H.L. Johnston, Low temperature heat capacities of inorganic solids. XIII. Heat capacity of lithium borohydride, J. Am. Chem. Soc. 75 (1952) 1496-1497.

[16] D.S. Stasinevich, G.A. Egorenko, Thermographic study of borohydrides of alkali metals and magnesium at pressures up to 10 atm, Russ. J. Inorg. Chem. 13 (1968) $341-343$.

[17] V.E. Gorbunov, K.S. Gavrichev, V.L. Zalukaev, G.A. Sharpataya, S.I. Bakum, Capacite' calorifique et transition de phase de borohydrure de lithium; Heat capacity and phase transition of lithium borohydride, Zh. Neorg. Khim. 29 (1984) 2333-2337.

[18] V.E. Gorbunov, K.S. Gavrichev, V.B. Lazarev, Thermodynamic properties and phase transitions of alkali metal borohydrides, Zh. Fiz. Khim. 60 (1986) $2067-2069$.

[19] A. El Kharbachi, I. Nuta, F. Hodaj, M. Baricco, Above room temperature heat capacity and phase transition of lithium tetrahydroborate, Thermochim. Acta 520 (2011) 75-79.

[20] SGTE, Substances Database v 4.1, In.

[21] NIST, Chemistry WebBook, In.

[22] M.W. Chase Jr., C.A. Davies, J.R. Downey Jr., D.J. Frurip, R.A. McDonald, A.N. Syverud, NIST-JANAF thermochemical tables, J. Phys. Chem. Ref. Data (1998) 9.

[23] K. Miwa, N. Ohba, S.-i. Towata, Y. Nakamori, S.-i. Orimo, First-principles study on lithium borohydride LiBH$_{4}$, Phys. Rev. B 69 (2004) 245120.

[24] D.J. Siegel, C. Wolverton, V. Ozolins, Thermodynamic guidelines for the prediction of hydrogen storage reactions and their application to destabilized hydride mixtures, Phys. Rev. B 76 (2007) 134102

[25] R. Caputo, A. Zuttel, First-principles study of the paths of the decomposition reaction of $\mathrm{LiBH}_{4}$, Mol. Phys. 108 (2010) $1263-1276$.

[26] S.H. Lee, V.R. Manga, Z.-K. Liu, Effect of Mg, Ca, and Zn on stability of $\mathrm{LiBH}_{4}$ through computational thermodynamics, Int. J. Hydrogen Energy 35 (2010) $6812-6821$.

[27] T.J. Frankcombe, G.J. Kroes, Quasiharmonic approximation applied to $\mathrm{LiBH}_{4}$ and its decomposition products, Phys. Rev. B 73 (2006) 174302.

[28] N. Ohba, K. Miwa, M. Aoki, T. Noritake, S. Towata, Y. Nakamori, S. Orimo,

A. Zuttel, First-principles study on the stability of intermediate compounds of $\mathrm{LiBH}_{4}$, Phys. Rev. B 74 (2006) 075110.

[29] M.B. Smith, G.E. Bass, Heats and free energies of formation of the alkali aluminum hydrides and of cesium hydride, J. Chem. Eng. Data 8 (1963) $342-346$.

[30] K.C. Kim, M.D. Allendorf, V. Stavila, D.S. Sholl, Predicting impurity gases and phases during hydrogen evolution from complex metal hydrides using free energy minimization enabled by first-principles calculations, Phys. Chem. Chem. Phys. 12 (2010) 9918-9926.

[31] D.D. Wagman, Thermochemical Data for Simple Hydrides and Inorganic Oxidizers, NBS Report no. 7437, 1962, pp. 79-95.

[32] J.H.E. Jeffes, H. McKerrell, The thermodynamics of hydrides, J. Iron Steel Inst. London 202 (1964) 666-676. 
[33] Y. Nakamori, K. Miwa, A. Ninomiya, H. Li, N. Ohba, S.-i. Towata, A. Zuttel, S.-I. Orimo, Correlation between thermodynamical stabilities of metal borohy-drides and cation electronegativites: first-principles calculations and experi-ments, Phys. Rev. B: Condens. Matter Mater. Phys. 74 (2006) 045126-045129.

[34] J.P. Soulie', G. Renaudin, R. Cerny', K. Yvon, Lithium boro-hydride LiBH4: I. Crystal structure, J. Alloys Compd. 346 (2002) $200-205$.

[35] E.M. Fedneva, V.I. Alpatova, V.I. Mikheeva, Thermal stability of lithium borohydride, Russ. J. Inorg. Chem. 9 (1964) $826-827$.

[36] C.W.F.T. Pistorius, Melting and polymorphism of lithium tetrahydroborate to 45 kbar, Z. Phys. Chem. 88 (1974) 253-263.

[37] F. Pendolino, P. Mauron, A. Borgschulte, A. Zuttel, Effect of boron on the activation energy of the decomposition of LiBH4, J. Phys. Chem. C 113 (2009) $17231-17234$.

[38] N.A. Zarkevich, D.D. Johnson, Predicting enthalpies of molecular substances: application to $\mathrm{LiBH}_{4}$, Phys. Rev. Lett. 100 (2008) 040602.

[39] H.I. Schlesinger, H.C. Brown, Metallo borohydrides. III. Lithium borohydride, J. Am. Chem. Soc. 62 (1940) 3429-3435.

[40] K.N. Semenenko, A.P. Chavgun, V.N. Surov, Reaction of sodium borohydride with potassium and lithium borohydrides, Russ. J. Inorg. Chem. 16 (1971) $271-273$.

[41] T.E.C. Price, D.M. Grant, I. Telepeni, X.B. Yu, G.S. Walker, The decomposition pathways for $\mathrm{LiBD}_{4}-\mathrm{MgD}_{2}$ multicomponent systems investigated by in situ neutron diffraction, J. Alloys Compd. 472 (2009) 559-564.

[42] Y. Filinchuk, D. Chernyshov, R. Cerny, Lightest borohydride probed by synchrotron X-ray diffraction: experiment calls for a new theoretical revision, J. Phys. Chem. C 112 (2008) 10579-10584.

[43] A. Zuttel, S. Rentsch, P. Fischer, P. Wenger, P. Sudan, P. Mauron, C. Emmenegger, Hydrogen storage properties of LiBH 4 , J. Alloys Compd. 356 (2003) 515-520. 
[44] P. Mauron, F. Buchter, O. Friedrichs, A. Remhof, M. Bielmann, C.N. Zwicky,

A. Zuttel," Stability and reversibility of $\mathrm{LiBH}_{4}$, J. Phys. Chem. B 112 (2008) 906-910.

[45] V. Ozolins, E.H. Majzoub, C. Wolverton, First-principles prediction of thermo-dynamically reversible hydrogen storage reactions in the Li-Mg-Ca-B-H system, J. Am. Chem Soc. 131 (2009) 230-237.

[46] S.I. Orimo, Y. Nakamori, N. Ohba, K. Miwa, M. Aoki, S. Towata, A. Zuttel, Experimental studies on intermediate compound of LiBH4, Appl. Phys. Lett. 89 (2006) 021920.

[47] S.J. Hwang, R.C. Bowman, J.W. Reiter, J. Rijssenbeek, G.L. Soloveichik, J.C. Zhao, H. Kabbour, C.C. Ahn, NMR confirmation for formation of $\left[\mathrm{B}_{12} \mathrm{H}_{12}\right]^{2}$ complexes during hydrogen desorption from metal borohydrides, J. Phys. Chem. C 112 (2008) 3164-3169.

[48] Y.G. Yan, H.W. Li, H. Maekawa, K. Miwa, S. Towata, S. Orimo, Formation of intermediate compound $\mathrm{Li}_{2} \mathrm{~B}_{12} \mathrm{H}_{12}$ during the dehydrogenation process of the $\mathrm{LiBH}_{4}-\mathrm{MgH}_{2}$ system, J. Phys. Chem. C 115 (2011) 19419-19423.

[49] O. Friedrichs, A. Remhof, S.J. Hwang, A. Zuttel, Role of $\mathrm{Li}_{2} \mathrm{~B}_{12} \mathrm{H}_{12}$ for the formation and decomposition of $\mathrm{LiBH}_{4}$, Chem. Mater. 22 (2010) $3265-3268$.

[50] M. Au, R.T. Walters, Reversibility aspect of lithium borohydrides, Int. J. Hydrogen Energy 35 (2010) 10311-10316.

[51] B. Sundman, B. Jansson, J.O. Andersson, The thermo-calc databank system, Calphad: Comput. Coupling Phase Diagrams Thermochem. 9 (1985) $153-190$.

[52] Thermocalc software. /http://www.thermocalc.com.InS.

[53] SGTE, Scientific Group Thermodata Europe, In.

[54] M.W. Chase, AI, A. Dinsdale, G. Eriksson, G. Grimvall, L. Hoglund,

H. Yokokawa, Group 1: heat capacity models for crystalline phases from 0 K to $6000 \mathrm{~K}$, Calphad: Comput. Coupling Phase Diagrams Thermochem. 19 (1995) $437-447$.

[55] J.O. Andersson, A.F. Guillermet, P. Gustafson, M. Hillert, B. Jansson, B. Jonsson,

B. Sundman, J. Agren, A new method of describing lattice stabilities, Calphad: Comput. Coupling Phase Diagrams Thermochem. 11 (1987) 93-98.

[56] S. Orimo, Y. Nakamori, G. Kitahara, K. Miwa, N. Ohba, S. Towata, A. Zuttel, Dehydriding and rehydriding reactions of $\mathrm{LiBH}_{4}$, J. Alloys Compd. 404 (2005) $427-430$.

[57] Y.G. Yan, A. Remhof, S.J. Hwang, H.W. Li, P. Mauron, S. Orimo, A. Zuttel,

Pressure and temperature dependence of the decomposition pathway of $\mathrm{LiBH}_{4}$, Phys. Chem. Chem. Phys. 14 (2012) 6514-6519.

[58] R. Gremaud, Z. Lodziana, P. Hug, B. Willenberg, A.M. Racu, J. Schoenes,

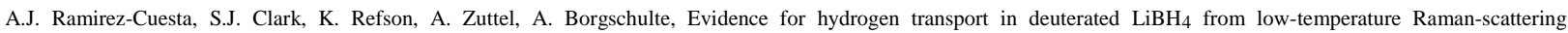
measurements and first-principles calculations, Phys. Rev. B (2009) 80.

[59] K.S. Gavrichev, Heat capacity and thermodynamic properties of inorganic compounds containing thetraedral anions, Inorg. Mater. 39 (2003) S89-S112.

[60] A. Zuttel, P. Wenger, P. Sudan, P. Mauron, S.I. Orimo, Hydrogen density in nanostructured carbon, metals and complex materials, Mater. Sci. Eng. B: Solid State Mater. Adv. Technol. 108 (2004) 9-18.

[61] J. Lang, A. Gerhauser, Y. Filinchuk, T. Klassen, J. Huot, Differential scanning

calorimetry (DSC) and synchrotron X-ray diffraction study of unmilled and milled $\mathrm{LiBH}_{4}$ : a partial release of hydrogen at moderate temperatures, Crystals 2 (2012) 1-21.

[62] F.D. Rossini, D.D. Wagman, W.H. Evans, S. Levine, I. Jaffe, Selected Values of Chemical Thermodynamic Properties, Circular of the National Bureau of Standards 500, US Government Printing Office, Washington, DC, 1952

[63] D.D. Wagman, W.H. Evans, V.B. Parker, R.H. Schumm, I. Halow, S.M. Bailey, K.L. Churney, R.L. Nuttall, J. Phys. Chem. Ref. Data 11(Suppl. 2); The NBS tables of chemical thermodynamic properties. Selected values for inorganic and C1 and C2 organic substances in SI units, Am. Inst. Phys. 1982.

[64] D. Reed, D. Book, Recent applications of Raman spectroscopy to the study of complex hydrides for hydrogen storage, Curr. Opinion Solid State Mater. Sci. 15 (2011) 62-72.

[65] T.J. Frankcombe, G.J. Kroes, A. Zuttel, Theoretical calculation of the energy of formation of $\mathrm{LiBH}_{4}$, Chem. Phys. Lett. 405 (2005) $73-78$.

[66] D.R. Lide, CRC Handbook of Chemistry and Physics, CRC Press, Taylor and Francis, Boca Raton, 2008 88th ed. 